\title{
PIPES E DIQUES DE BRECHA - UM NOVO MODELO DE ORIGEM (IMPLOSÃO - FLUIDIZAÇÃO)
}

\author{
JOÃO C. BIONDI*
}

\begin{abstract}
A new physical emplacement model is proposed for the vertical breccia formation, such as kimberlitic and breccia dykes. They would form in two phases: - A first one, called the implosion phase, leads to the formation of vertical pipes filled by breccia that were formed by a phreatic implosion caused by heating of water in sediments as a result of an ascending lava front. The second one, called the fluidization phase, leads to breccia evolution and characterization of them as pipe breccia. Fluidization can be explained only by the great volume of moist discharged during the initial implosive phase, even if the contribution of volcano-magmatic gases is not considered. Both phases are dimensioned with basis on a geological-grannulometric study made over breccia pipes and a breccia dyke of the Lodève region, France. All the emplacement stages are calculated and the results are compared with equivalent cases measured on recent volcanic occurrences.
\end{abstract}

INTRODUÇÃo Após a descoberta dos kimberlitos, as teorias sobre a gênese destas formações váriaram conforme o autor, ultimamente sendo dada mais ênfase à ação de correntes de gás com poder perfurante. As teorias mais antigas, ditas "de explosão", tiveram dificuldades na explicação de fatos tais como:

a) Diâmetro reduzido dos pipes em relação ao comprimento. mações.

b) A gênese das brechas que preenchem estas for-

c) O arredondamento importante dos elementos de brecha. líticas.

d) A gênese da matriz das brechas tipo kimber-

Uma variedade moderna das teorias "de explosão", é a que admite um front de lava que se deslocaria a grande velocidade. Primeiramente defendida por russos (Mikeyenko e Nenashev, 1960), esta teoria foi reconsiderada por McGetchin $(1972,1973)$ que a simulou em computador. A noção de fluidização foi introduzida em geologia por Reynolds (1954), que a utiliza na explicação da formação de plutões graní ticos. Dawson (1962) ligou a fluidização, pela primeira vez, à gênese das chaminés de brecha. Após, a ação empreendida por uma mistura gás-sólido na fase de brechiação das chaminés foi cada vez mais reconhecida, ainda que vários problemas restem sem solução:

a) Fisher (1955) demonstra a impossibilidade do alargamento de fissuras de uma rocha pela simples percolação de uma corrente de gás. A velocidade necessária somente é atingida na zona de descom. pressão, a alguns metros antes da superficie. b) Ainda que se admita "a priori" a ação de uma corrente de gás com capacidade erosiva, é necessário encontrar a fonte do volume de gás necessário. McBirney (1963) demonstrou a impossibilidade que têm os corpos magmáticos de semi-profundidade de originarem tais volumes de gás unicamente por resfriamento e separação da fase fluida.

c) Shimazu (1961, in Bardet, 1973) mostra a impossibilidade de um gás a alta temperatura se acumular em profundidade, considerando a forte difusividade de gases aquecidos nas rochas.

d) Tendo-se em conta o tempo necessário para que uma corrente gasosa possa perfurar por erosão um orificio das dimensões de um pipe, seria normal a existência de sinais de ação termometamórfica. Kennedy e Nordlie (1968) demonstraram que raramente houve temperaturas de mais de $200^{\circ} \mathrm{C}$ durante a gênese dos pipes.

e) É necessária uma explicação para as "gotas" (gouttellettes, de Lorenz et al., 1970); que seriam elementos de brecha com formas fluidas caprichosas, típicas da solidificação rápida de um corpo fluido, encontradas a grandes profundidades nos pipes. Deve-se também explicar a predominância de elementos de brecha de composiçâo basáltica, geralmente constatada nas brechas de pipe.

Em 1963, McBirney introduz a noção de explosão freática para a origem das formações de brecha. Com base nas informações transmitidas por Goguel (1953), o autor apresenta um mecanismo de origem bem descrito por Lorenz et al., (1970). Este mecanismo explicaria somente a formação de pipes pouco profundos, com forma afunilada e de grande diâmetro. Este tipo de estrutura existe, tendo sido descrito por Bardet 
(1973) na região central da África, mas não corresponde à forma cilíndrica mostrada pela maioria das formações até hoje estudadas. Restaria ainda a explicar a observação de que todos os kimberlitos têm, em profundidade, uma forma cilíndrica que evolui, na raiz, para um dique e não para um plutão (Nixon et al., 1973, Bardet, 1973). Um último problema seria a explicação para a gênese dos pipes "cegos", que não atingem a superficie. $\mathrm{O}$ modelo aqui proposto deriva também dos estudos de Goguel (1953) sobre as explosões freáticas.

\section{Modelo de implosão - fluidizaçáo FASE}

IMPLOSIVA A implosão, ao contrário da explosão, é o conjunto de ações violentas que conduzem a concentração de material em uma região determinada.

Este modelo considera os últimos $1500 \mathrm{~m}$ de um front magmático que sobe a uma velocidade de $15 \mathrm{~m} /$ dia (McBirney, 1959) e que tem a lava com, temperatura variando como o determinou McBirney (1970, pp. 377) para um basalto saturado a $1 \%$ de água. Será admitido que o front magmático se introduz em sedimentos fraturados que contêm $10 \%$ de água em superficie e $2 \%$ a $1500 \mathrm{~m}(0,54 \%$ por $100 \mathrm{~m})$. $\mathrm{O}$ terreno tem uma certa porosidade e uma baixa permeabilidade, o que impediria a formação de correntes de convecção e a rápida migração da água aquecida nos poros da rocha. $O$ modelo consiste em provar que o aquecimento da água na encaixante do front de lava pode dar origem a uma quantidade de energia potencial, que é mais que suficiente para desagregar violentamente as rochas próximas do contato e para brechiar toda a coluna, desde que haja uma descompressão (dètente) no sistema que permita a vaporização da água aquecida.

1) As isotermass Um front magmático subindo com velocidade média de $15 \mathrm{~m} /$ dia, aquecerá durante 100 dias a encaixante situada a $1500 \mathrm{~m}$ de profundidade, contra um só dia nos últimos $15 \mathrm{~m}$. Uma lava saturada a $1 \%$ de água terá a seguinte temperatura (McBirney, 1970):

\begin{tabular}{ccc}
\hline $\begin{array}{c}\text { Profundidade } \\
\text { em metros }\end{array}$ & $\begin{array}{c}\text { Temperatura da } \\
\text { lava em }{ }^{\circ} \mathrm{C}\end{array}$ & $\begin{array}{c}\text { Temperatura no } \\
\text { contato } \\
\text { lava/encaixante }\end{array}$ \\
\hline Superficie & $800^{\circ} \mathrm{C}$ & $400^{\circ} \mathrm{C}$ \\
150 & $900^{\circ} \mathrm{C}$ & $450^{\circ} \mathrm{C}$ \\
375 & $1000^{\circ} \mathrm{C}$ & $500^{\circ} \mathrm{C}$ \\
1500 & $1100^{\circ} \mathrm{C}$ & $550^{\circ} \mathrm{C}$ \\
\hline
\end{tabular}

Toda a encaixante será considerada, para efeito pessimista de cálculo, a uma temperatura inicial de $0{ }^{\circ} \mathrm{C}$ não importa a que profundidade. Jaeger (in Poldervaart, 1968) demonstra que sob estas condições uma rocha qualquer terá, no contato com um corpo intrusivo, a metade da temperatura deste corpo imediatamente após a sua intrusão, o que corresponde, portanto, à metade das temperaturas da lava, acima relatadas, nas profundidades correspondentes.

A posição no tempo de uma isoterma que se desloca de uma região fonte de calor pode ser calculada a partir das equações de Jaeger:

$$
\frac{T}{T_{0}}=\frac{1}{2}-\frac{1}{2} \quad \text { erf } \frac{x}{2\left(K_{4}\right)^{1 / 2}}
$$

$$
\operatorname{erf} u=\frac{2}{\pi^{1 / 2}} \int_{0}^{u} \quad e^{-z^{2}} d z
$$

Nesta equação, $T$ é a temperatura da isoterma que se quer locar e $T_{0}$ a temperatura no contato. Para uma mesma difusividade $K$ para a lava e a encaixante, $T$ é a temperatura de um ponto a $\mathrm{X}$ unidades de distância após um tempo $t$. O valor "erf $u$ " é a "função erro" ("error function") encontrada em tabelas de constantes.

O Quadro 1 mostra a distância do contato das isotermas $200^{\circ} \mathrm{C}$ e $150^{\circ} \mathrm{C}$ segundo o modelo da Fig. 1 . Será considerada, novamente em cálculo pessimista, como não aproveitável a energia possível de se originar pela vaporização da água contida fora da região limitada pela superficie isotérmica de $150^{\circ} \mathrm{C}$. A temperatura do contato, que deve aumentar com o tempo de aquecimento, será admitida como invariável, calculando-se, portanto, a distância mínima de migração das isotermas.

Quadro I - Distância do contato das isotermas $200^{\circ} \mathrm{C}$ e $150^{\circ} \mathrm{C}$

\begin{tabular}{c|c|c}
\hline $\begin{array}{c}\text { Profundidade } \\
(\mathrm{m})\end{array}$ & $\begin{array}{c}X_{200}(\mathrm{~m}) \\
(\mathrm{c})\end{array}$ & $\begin{array}{c}X_{350 \%}(\mathrm{~m}) \\
(\mathrm{m})\end{array}$ \\
\hline 15 & 0,1 & 1,2 \\
150 & 1,8 & 6,8 \\
375 & 5,3 & 10,9 \\
750 & 8,3 & 16,6 \\
1500 & 12,0 & 24,0 \\
\hline
\end{tabular}

2) Energias disponiveis e as forças de resistência do sistema Um ponto $P$ qualquer (Fig. 2), distante $P M$ do contato com a intrusão e situado dentro do volume delimitado pela isoterma $150^{\circ} \mathrm{C}$, terá energia potencial devida a possivel vaporização da água contida na rocha onde se encontra $P$. O sistema tem dois pontos ou bases de apoio, $S_{1}$ e $S_{2}$, a energia nula, onde $S_{1}$ tem energia nula devido ao aumento da resis- 


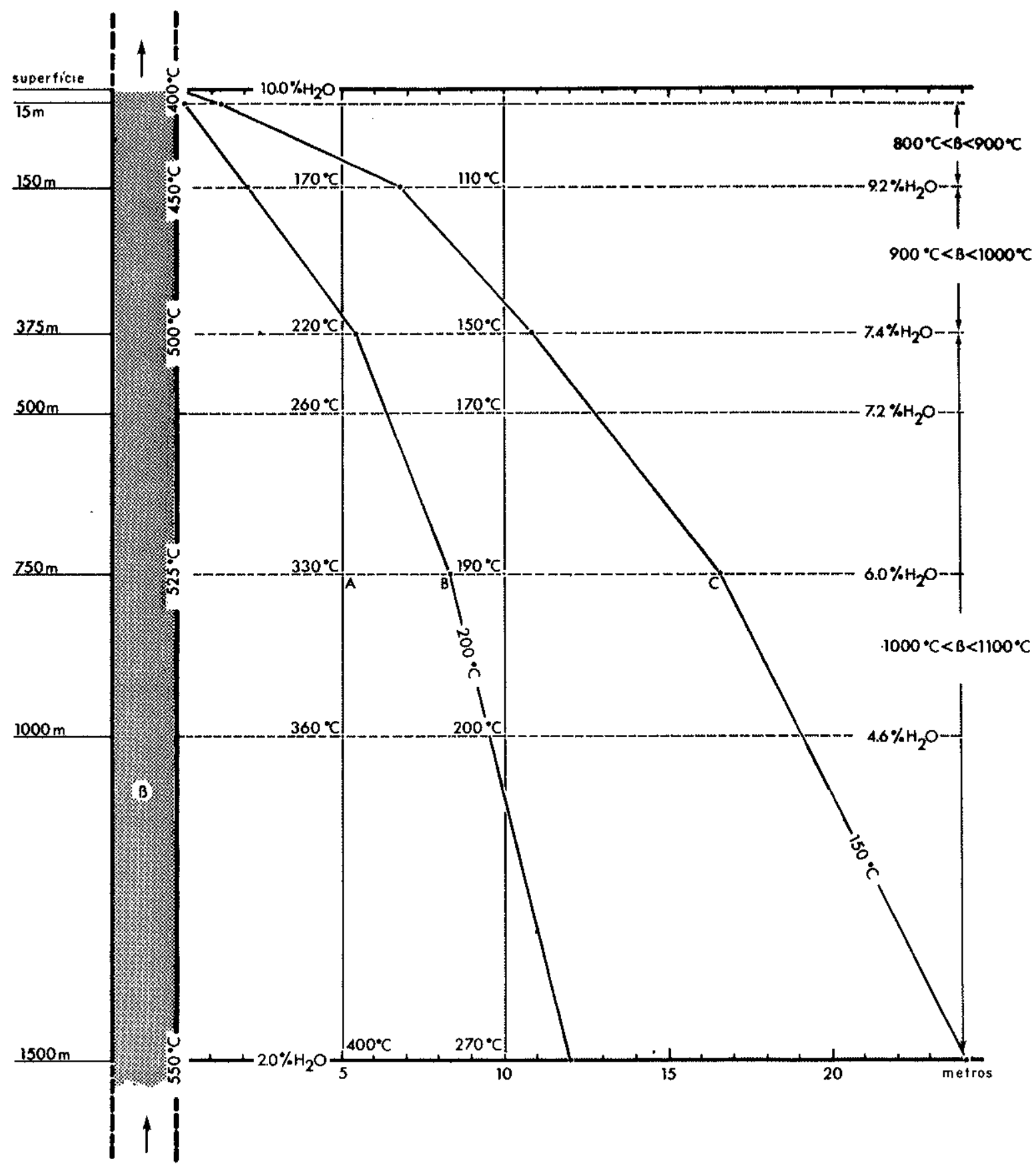

Figura 1 - Modelo térmico adotado para o sistema de implosão-fluidização. A posição das isotermas e as porcentagens de água na encaixante, são mostradas a diferentes profundidades

tência da rocha com a profundidade e $S_{2}$ tem energia nula pela falta de água aquecida a mais de $150^{\circ} \mathrm{C}$. É, portanto, possível repartir as forças ativas neste sistema em um sistema ortogonal. Sobre o ponto $P$ será considerada a ação de uma força com uma componente vertical $W_{v}$, apoiando-se sobre $S_{1}$, e outra horizontal $W_{\mathrm{h}}$, apoiando-se sobre $S_{2}$. Com ação oposta a $W_{\mathrm{v}}$ e $W_{\mathrm{h}}$ serão considerados:

$P_{\mathrm{s}}$ : peso da coluna de sedimentos sobre $P$

$P_{11}$ : pressão devida ao peso da coluna de lava na profundidade $P$. Ela é ativa em todos os sentidos
$P_{\mathrm{c}}$ : força de coesão da rocha. Pressão necessária ao vapor d'água para desagregar a rocha onde se encontra $P$. Força ativa em todos os sentidos

Será calculada a resultante das forças definidas no sistema para que se possa julgar o efeito destas forças sobre o ambiente onde o sistema se desenvolve. Deve-se fazer notar que mesmo se a energia disponível for infinitamente superior às forças oponentes, haverá explosão somente se houver uma descompressão no sistema, permitindo a vaporização da água aquecida a mais de $150^{\circ} \mathrm{C}$. 
Superficie

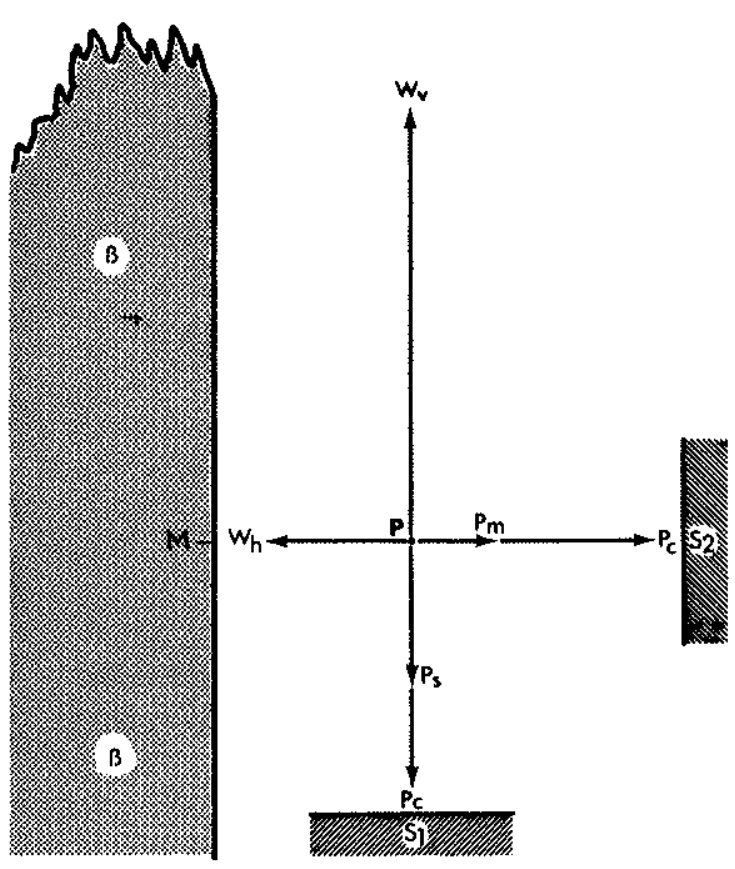

Figura 2 - Sistema de forças considerado para os cálculos. As forças ativas segundo a horizontal (perpendiculares ao plano da figura) anulam-se entre si, o sistema podendo ser considerado ortogonal

2a) Energia vertical $W_{\mathrm{v}} \quad$ A uma mesma profundidade esta energia é variável com a distância ao contato da intrusão, com a posição do ponto na isoterma e com a percentagem de água do terreno na profundidade considerada.

Os valores das energias foram lidos diretamente no gráfico dado por Goguel $(1953$, p. 28$)$. Será admitida uma variação progressiva da temperatura entre o conta to e a isoterma $200^{\circ} \mathrm{C}$, e entre as duas isotermas. Será considerada, para simplificação de cálculo e pessimização do sistema, somente a energia vertical disponivel entre o contato e uma superficie distante $10 \mathrm{~m}$. Notar (Fig. 1) que isto é apenas uma parte do total de energia disponível, visto que a superficie $10 \mathrm{~m}$ corta aquela da isoterma $150^{\circ} \mathrm{C}$ a $325 \mathrm{~m}$ de profundidade. A Fig. 3 resume os resultados calculados segundo as simplificações mencionadas.

Admitindo-se a variação de percentagem de água descrita (Fig. 1), ter-se-ia a encaixante seca a $1870 \mathrm{~m} . W_{\mathrm{v}}$ a $1500 \mathrm{~m}$ será considerada como tendo sua energia proveniente de uma coluna de $300 \mathrm{~m}$ de altura, com $1 \%$ de água e temperatura no contato de $550^{\circ} \mathrm{C}$. Na Fig. 3, a subtração das energias lidas em dois pontos diferentes dá a quantidade de energia disponível entre estes dois pontos.

2b) Energia horizontal $W_{\mathrm{b}} \quad$ Variando-se a percentagem de água com a profundidade e a temperatura com a distância do contato, calcula-se a energia contida na região aquecida a mais de $150^{\circ} \mathrm{C}$, os resultados

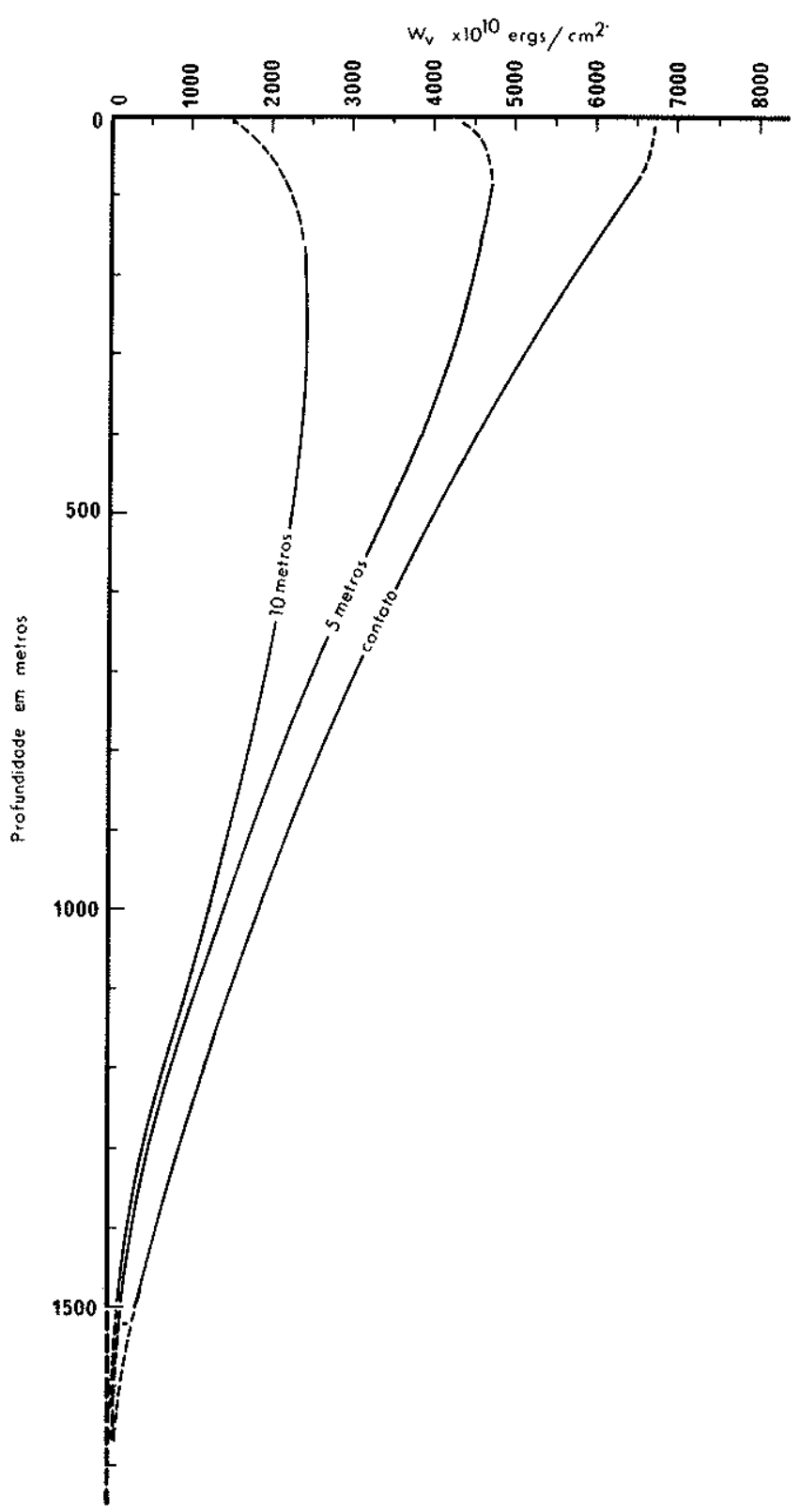

Figurd 3-Curvas cumulativas das energias disponíveis na encaixante junto ao contato, a 5 e a $10 \mathrm{~m}$ da intrusão. $\hat{E}$ a energia que dará origem às forças ativas segundo a vertical $\left(W_{\mathrm{v}}\right)$

estando resumidos na Fig. 4. Notar nesta figura que a profundidade para a qual é máxima a resistência da rocha a uma distância dada do contato é determinada pelo cruzamento da curva de energia correspondente a esta distância com o eixo de ordenadas. A coluna sobre este ponto é um "peso morto" para a energia correspondente à curva respectiva. A integração da superficie da curva de energia a partir do contato dará $W_{\mathrm{h}}$ total do sistema. Para o cálculo de $W_{\mathrm{h}}$ contido entre dois pontos, à mesma profundidade, distantes A e B do contato, basta ler a energia do ponto A depois de $B$ e subtraí-las. 


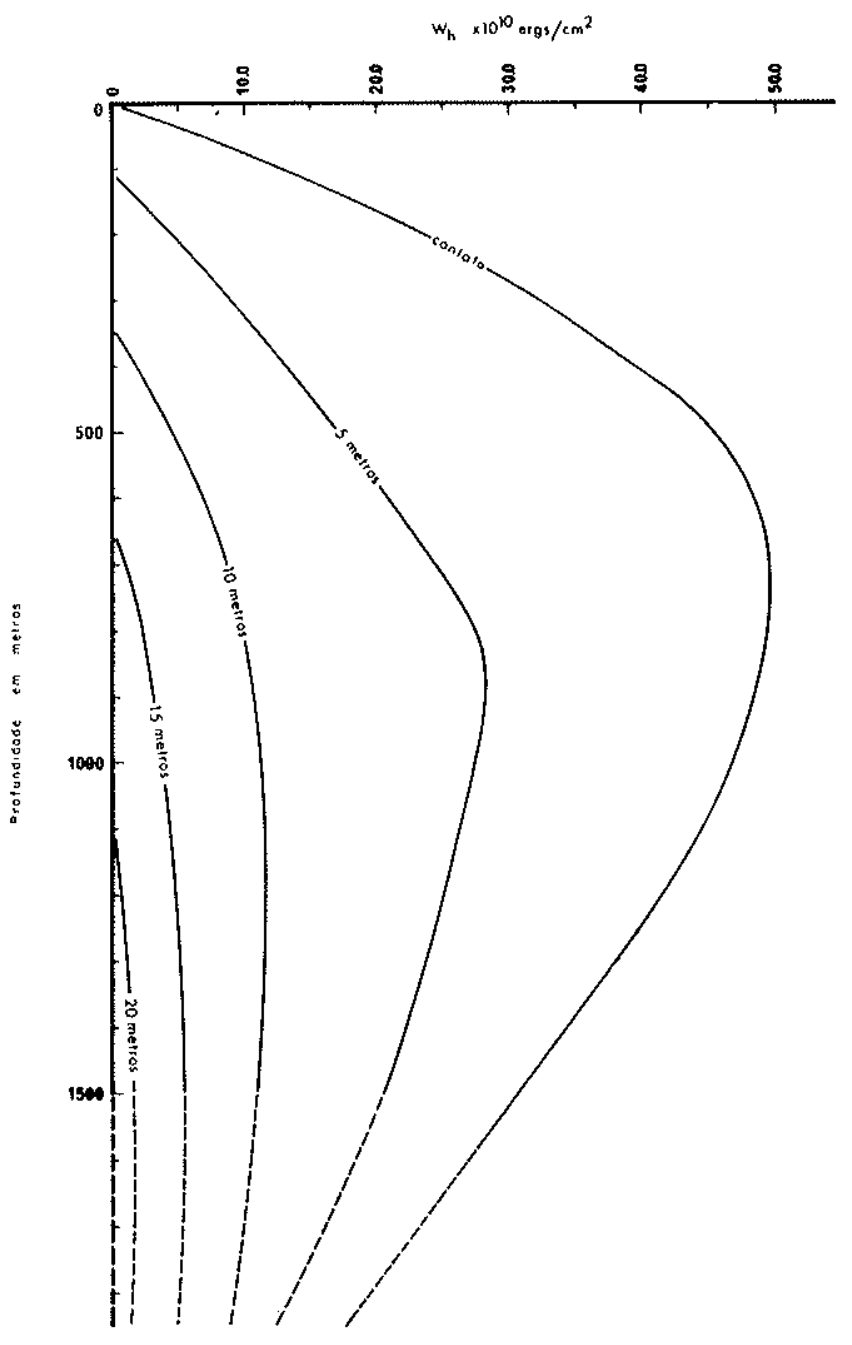

Figura 4-Curvas cumulativas de variação de energia disponível segundo a horizontal $\left(W_{h}\right)$ para diferentes profundidades e distâncias do contato com a intrusão. A integração da superficie da curva de energia do contato dará Wh total do sistema

2c) Força devida ao peso da coluna sedimentar $P_{\mathrm{s}}$ O peso sendo $P=V_{\mathrm{ak}}$ e a pressão por unidade de superficie sendo $p=h_{\mathrm{dg}}(V=$ volume, $d=$ densidade, $h=$ altura da coluna entre um ponto e a superficie) se se considera $d=2,7 \mathrm{~g} / \mathrm{cm}^{3}$, igual para a coluna de lava e para o sedimento, as duas equações acima permitem a construção da Fig. 5, curva denominada "coluna sedimentar".

2d) Força devida ao peso da coluna magmática $P_{\mathrm{m}}$ Para uma mesma densidade da lava e da encaixante, o peso de uma coluna de lava que sobe com velocidade $V$ é diferente daquela da encaixante e também diferente da mesma coluna de lava quando estática.
Se se considera $W$ o trabalho realizado pela pressão magmática para descolar uma coluna de lava a uma altura $h$.

$$
W=m g d
$$

Se $W_{\mathrm{c}}$ for a energia cinética da coluna, $W_{\mathrm{c}}=$ $=1 / 2 m v^{2}, v$ correspondendo a velocidade alcançada pela coluna, e $W=W_{\mathrm{c}}$ ou

$$
m g h=1 / 2 m v^{2} \quad v=(2 h g)^{1 / 2}
$$

que é a velocidade necessária (impulso) para levantar uma coluna de lava de massa $m$ a uma altura $h$.

Sem friç̧ão com as paredes, e a viscosidade sendo considerada nula, a pressão magmática $P$ para imprimir $V$ a coluna será:

$$
P=\frac{F}{S} \therefore F=P S \quad \begin{aligned}
& F=\text { Força necessária } \\
& S=\text { Seção da coluna }
\end{aligned}
$$

O trabalho realizado pela força $F$, segundo a distância $h$ correspondente à altura a que a lava é lançada acima da superfície é

$$
W=P S h
$$

que é igual à energia cinética, portanto, $P S h=1 / 2 m v^{2}$ ou então,

$$
P=\frac{m v^{2}}{2 h S} \therefore P=\frac{m v^{2}}{2 h}
$$

quando se considera uma secção $S$ de base unitária. Considerando-se $m=h d$ (base unitária):

$$
P=\frac{v^{2} d}{2} \quad d=\text { densidade }
$$

As Eqs. (3) e (6) permitem a determinação da pressão magmática necessária para acelerar uma coluna de base unitária a uma velocidade $V$ e lançá-la a uma altura $h$. Para uma mesma densidade do sedimento e da lava, a subtração entre o peso da coluna a qualquer profundidade e a pressão correspondente à mesma profundidade a uma velocidade dada, determina as duas curvas da Fig. 5, calculadas quando a lava é lançada a 50 e a $100 \mathrm{~m}$ de altura. A Fig. 5 permite saber, a uma mesma profundidade, qual é a diferença de peso entre a coluna magmática estática (curva coluna sedimentar) e quando acelerada a $30 \mathrm{~m} / \mathrm{s}$ ou a $44,3 \mathrm{~m} / \mathrm{s}$.

Notar (Fig. 5) que para uma velocidade de $30 \mathrm{~m} / \mathrm{s}$, a pressão se anula a $450 \mathrm{~m}$ de profundidade, o que mostra que o peso de $450 \mathrm{~m}$ da coluna de lava é igual à pressão magmática necessária para acelerar a mesma coluna a uma velocidade de $30 \mathrm{~m} / \mathrm{s}$. Portanto, a menores profundidades $P_{\mathrm{m}}$ será "nulo", a pressão da lava contra as paredes do conduto deixa de existir e 


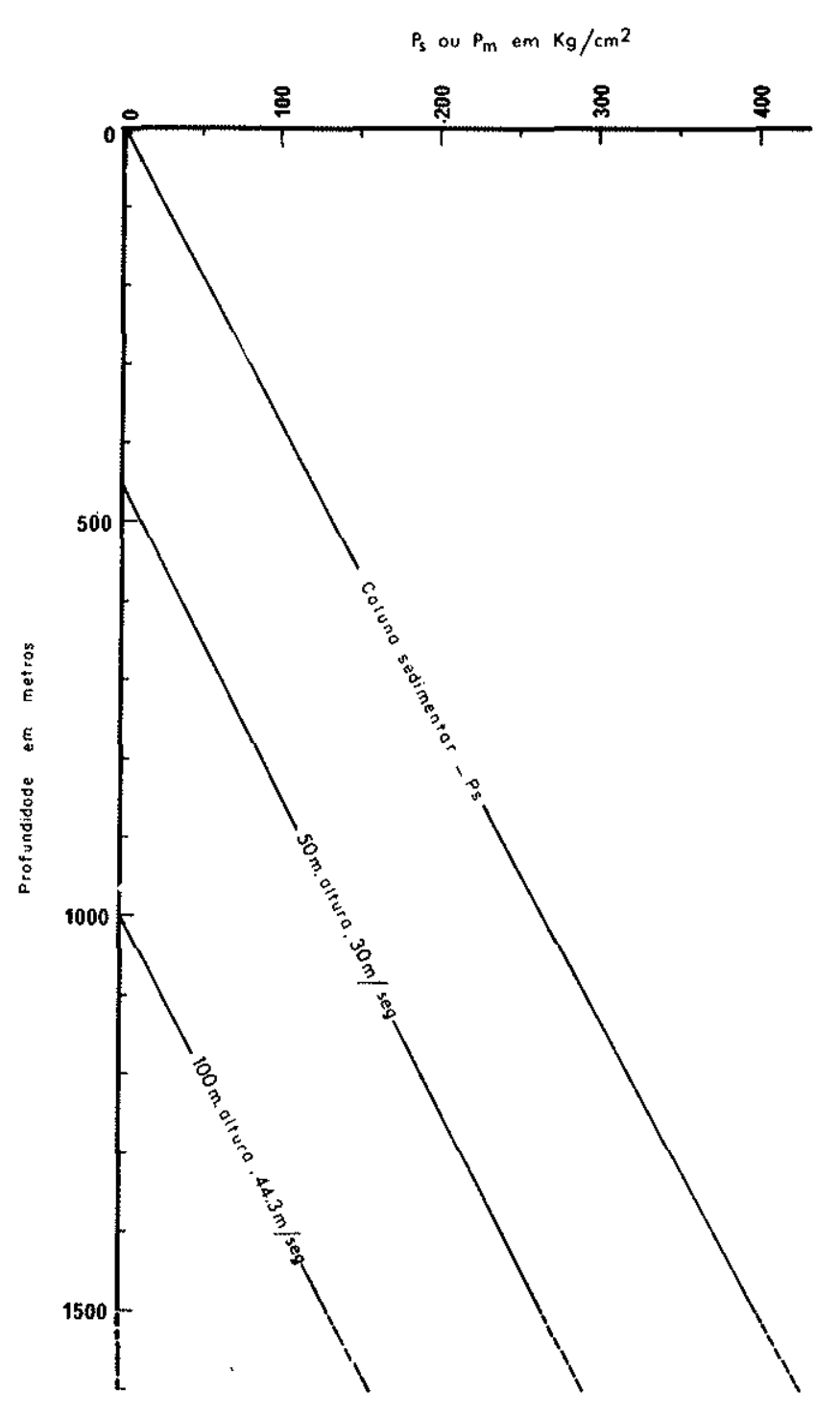

Figura 5- Peso da coluna de rocha encaixante e peso relativo de uma coluna magmática que sobe com velocidades de $30 \mathrm{~m} / \mathrm{s}$ ou $44,3 \mathrm{~m} / \mathrm{s}$. Ver texto para explicação

se transforma em força de "sucção". Quanto mais próximo da superficie, mais esta pressão se faz "negativa", em favor da ação de $W_{v}$. Este mecanismo será considerado para explicar o aparecimento de uma descompressão no sistema.

2e) Força de coesão $P_{\mathrm{c}} \quad$ Os valores procurados são sempre determinados experimentalmente, por medida direta, dado que o número de variáveis envolvido impede qualquer cálculo teórico. Um sistema que considere uma rocha porosa com vapor d'água preenchendo seus poros corresponde a um sistema de distensão. Talabre (1969) mediu a força de tração necessária para desagregar uma rocha segundo um sistema uniaxial. As pressões necessárias variam entre 100 bars para um granito ou um basalto e 5 bars para um calcáreo. Para os cálculos a seguir, será considerada uma pressão de 25 bars $\left(26 \mathrm{~kg} / \mathrm{cm}^{2}\right)$ segundo a horizontal e a vertical (notar a existência de um aumento da coesão das rochas com a profundidade).

3) $O$ mecanismo de erupção A condição fundamental para que ocorra uma explosão no sistema descrito é a formação de uma zona de descompressão (Goguel, 1953).

Se uma coluna de lava é acelerada até a velocidade de $30 \mathrm{~m} / \mathrm{s}$ ela será lançada a $50 \mathrm{~m}$ de altura (Fig. 5). Para esta velocidade de ascensão, a partir de $450 \mathrm{~m}$ de profundidade até a superfície haverá uma região onde a pressão sobre as paredes do conduto será nula, criando nessa região uma zona de descompressão perfeita. Toda a coluna de rocha encaixante, superaquecida entre a superficie e $450 \mathrm{~m}$ de profundidade, deverá, portanto, explodir devido a brusca vaporização da água superaquecida. No dimensionamento dos efeitos desta explosão, tem-se:

- Coluna de rocha encaixante da superficie até $450 \mathrm{~m}$ de profundidade:

A Fig. 3 mostra as energias $W_{v}$ disponiveis na superficie e a $450 \mathrm{~m}$. A diferença da média das energias no contato, a $5 \mathrm{~m}$ e a $10 \mathrm{~m}$, medidas na superficie e a $450 \mathrm{~m}$ de profundidade resulta em $W_{\mathrm{v}}$ dos primei$\operatorname{ros} 450 \mathrm{~m}$ da coluna, que. corresponde a $1400 \times$ $\times 10^{10} \mathrm{erg} / \mathrm{cm}^{2}$. $\mathrm{O}$ ponto máximo de energia horizontal é a $450 \mathrm{~m}$ (Fig. 4), com o valor de $4000 \times$ $\times 10^{8} \mathrm{erg} / \mathrm{cm}^{2}$. A resultante de $W_{\mathrm{v}}+W_{\mathrm{h}}$ é um vetor energia $1406 \times 10^{10} \mathrm{erg} / \mathrm{cm}^{2}$ dirigido de $1^{\circ} 48^{\prime}$ para $o$ interior da coluna.

As forças que se opõem ao vetor energia calculado são (Fig. 5): $P_{\mathrm{s}}=120 \mathrm{~kg} / \mathrm{cm}^{2}, P_{\mathrm{c}}$ horizontal $=$ $=26 \mathrm{~kg} / \mathrm{cm}^{2}, P_{\mathrm{c}}$ vertical $=26 \mathrm{~kg} / \mathrm{cm}^{2}$ e a pressão magmática que é nula, visto se estar em região de descompressão. A resultante destas forças calculada na mesma direção de $W_{\mathrm{v}}+W_{\mathrm{h}}$ totaliza $145 \mathrm{~kg} / \mathrm{cm}^{2}$.

A energia de $1406 \times 10^{10} \mathrm{erg} / \mathrm{cm}^{2}$ liberada contra um "peso" de $145 \mathrm{~kg} / \mathrm{cm}^{2}$ pode acelerá-lo até a velocidade de $139,2 \mathrm{~m} / \mathrm{s}(500,4 \mathrm{~km} / \mathrm{h})$ e projetá-lo a uma altura de $1976 \mathrm{~m}$. Lorenz et al., (1970) mediram, a partir da distância de lançamento de blocos durante uma erupção, a sua velocidade de lançamento, tendo encontrado uma velocidade máxima de $200 \mathrm{~m} / \mathrm{s}$ $(720 \mathrm{~km} / \mathrm{h})$, o que situa o valor anteriormente calculado em uma média compatível.

Após a explosão, o volume de material expelido será considerado igual ao volume médio da matriz das brechas de explosão, próximo de $40 \%$ (Biondi, 1974). O sistema será, portanto, diminuído de $40 \%$ do peso inicial dos seus primeiros $450 \mathrm{~m}$, prolongando a zona de descompressão de $40 \%$ dos $450 \mathrm{~m}$ iniciais 
( $180 \mathrm{~m})$ o que transfere a base da descompressão para $630 \mathrm{~m}(450+180)$ de profundidade. Na realidade, a segunda zona de descompressão se forma instantaneamente, após a primeira explosão, o raciocínio desenvolvido devendo ser considerado um artificio de avaliação.

- Coluna de rocha entre 450 a $630 \mathrm{~m}$ de profundidade:

O mesmo tipo de cálculo acima desenvolvido mostra $\overrightarrow{W_{v}}+W_{\mathrm{b}}=673 \times 10^{10} \mathrm{erg} / \mathrm{cm}^{3}$, dirigido de menos de um grau para o interior da formação. As forças que se opõem a esta energia, calculadas na mesma direção de $W_{\mathrm{v}}+W_{\mathrm{h}}$ são de $146,6 \mathrm{~kg} / \mathrm{cm}$. Este "peso" pode ser acelerado até a $96,0 \mathrm{~m} / \mathrm{s}$ $(344,3 \mathrm{~km} / \mathrm{h})$ e lançado a $462 \mathrm{~m}$ de altura, caso seja liberada a energia disponível. Considerando-se as perdas de energia devidas aos choques entre partículas e à fricção com as paredes, dificilmente esta segunda explosão poderá projetar algum material em superfície. Toda a energia e o vapor liberados serão disponíveis para a fluidização da brecha formada pelas explosões. Outras explosões ocorrerão, cada uma liberando a energia disponível em uma coluna de altura aproximadamente igual a $40 \%$ da coluna que explodiu anteriormente. Sequiências de explosões em erupções vulcânicas foram registradas por McBirney (1959) e por Bowes e Wright (1967).

A velocidade de $30 \mathrm{~m} / \mathrm{s}$ limita as explosões e a brechiação até 800-900 metros de profundidade. Para velocidades próximas de $44 \mathrm{~m} / \mathrm{s}$, tem-se uma zona de brecha de $1700-1800$ metros. Os pipes kimberlíticos lavrados mostram brechas até a 2000 metros, o que corresponde a velocidade de lançamento de lava próximas de $48 \mathrm{~m} / \mathrm{s}$. Com esta velocidade, as lavas seriam lançadas a 120 metros de altura, o que é perfeitamente possivel, conforme observado nas erupções vulcânicas àtuais.

4) Chaminés de brecha que não chegam em superficie Considere-se um front de lava que sobe aproveitandose de zonas de fraturas. A descompressão necessária à implosão ocorrerá antes da lava atingir a superfície, no caso em que houver uma diminuição da pressão da câmara magmática que tenha como conseqüência uma diminuição importante da pressão exercida sobre a coluna em ascensão, com um eventual recuo desta. Dada a diferença de volume de lava entre a câmara magmática e a coluna, uma pequena variação de volume da primeira se refletirá drasticamente na outra. Rittmann (1963, pp. 321-347) constatou, diversas vezes, recuos deste tipo em chaminés aflorando sob a forma de lagos de lava.

5) Vantagens do modelo $\mathrm{O}$ modelo de implosão demonstra a possibilidade de formação de uma coluna de brecha (pipe ou dique), com a única intervenção de energias internas do sistema proveniente do aquecimento da água dos sedimentos pelo calor de uma intrusão de lava. O sistema proposto resolve as objeções feitas no começo, a saber:

a) Não é um fluxo de gás que abre o caminho para os pipes chegarem à superficie, mas sim um front de lava a alta temperatura e grande densidade.

b) A energia de brechiação é proveniente da água superaquecidános poros da rocha. $O$ gás, vapor d'água mais $\mathrm{CO}_{2}$, fluidiza uma brecha já formada segundo o mecanismo de implosão.

c) Ao vapor d'água proveniente das encaixantes e dos pedaços da encaixante que formam a brecha, adiciona-se $\mathrm{OCO}_{2}$ magmático dando origem ao volume de gás necessário para fluidizar o sistema. Cálculos a seguir o provarão.

d) A ação turbilhonar e as temperaturas presentes devem provocar o arredondamento dos elementos de brecha e alisar as paredes do conduto do pipe. O turbilhonamento e as implosões provocam a "aerosolisação" das lavas e a formação das "gotas".

e) O metamorfismo de contato inexiste por que o contato final, após as imploṣões e a fluidização, é distante do primeiro contato com as lavas, antes das implosões.

f) Em profundidade, onde as implosões começam a desaparecer, a "raiz" da formação é laminar, copiando a fissura original onde a lava se introduziu durante a fase de ascensão. Este tipo de enraizamento foi observado em todos os pipes kimberlíticos lavrados até grandes profundidades (Nixon et al. 1973, Bardet, 1973).

Os motivos pelos quais raramente as intrusões de lava se transformam em pipes podem ser:

a) O terreno onde ocorre a intrusão deve conter água a grandes profundidades. Isto seleciona os sedimentos como envelopes preferidos dos pipes.

b) O terreno deve ser pouco permeável para que não haja formação de correntes de convecção $e$, em seguida, dispersão da energia de vaporização com a migração da água. Isto explica a preferência dos pipes de se formarem dentro de formações calcáreas e pelíticas. Em uma mesma região, uma zona pouco fissurada (pouco permeável) terá um pipe, enquanto que nas regiões de falha ocorrerão os diques. Os diques estarão sempre perto das falhas e os pipes estarão próximos mas distantes do eixo principal de falhamento (zona de grande permeabilidade).

c) A coluna de lava deve subir lentamente a fim de que haja tempo para aquecer a água dos poros da rocha encaixante. Deve ter dimensões reduzidas, caso contrário as implosões não serão suficientemente fortes para estancar o fluxo de lava originando uma chaminé de brecha. Isto explica o pequeno diâmetro dos pipes.

Será demonstrado que o volume de vapor d'água conseqüente das implosões é suficiente para originar um sistema de fluidização capaz de erodir os elementos de brecha, alisar as paredes das chaminés e "aerosolisar" a lava originando as "gotas". 
FASE DE FLUIDIZAÇÃO A intenção de elaborar um modelo físico para a origem das chaminés de brecha exigiu um conhecimento quantitativo das brechas de pipe. Um estudo granulométrico é essencial.

1) Estudo Granulométrico Exclui-se imediatamente a técnica clássica de moagem e peneiramento usada em sedimentologia visto que a dimensão, a eventual aưréola de metamorfismo, a angulosidade e o fraturamento dos elementos de brecha impõem modificações importantes sobre os parâmetros granulométricos destes elementos. Esta técnica tem, também, a desvantagem de não permitir a determinação de parâmetros importantes tais como a "porosidade" (razão elementos-matriz) e a quantidade e o volume total de elementos de um tipo determinado.

Para a obtenção de todas estas informações, adaptou-se a técnica de contagem de pontos em lâmina delgada. Sobre uma superficie serrada da amostra de brecha, com a ajuda de uma folha de papel milimetrado transparente, mede-se o diâmetro e a superficie ocupada no plano para cada elemento de cada espécie existente e, evidentemente, a superficie total trabalhada. Os elementos foram divididos em três tipos: basálticos correspondentes às lavas, nódulos de peridotito e charnoquito; carbonatados para os calcários, dolomitos e arenitos; e pelíticos para os pelitos e xistos. Este tipo de medida com o papel milimetrado, é feito para os elementos maiores ou iguais a 1 milimetro. $O$ volume da matriz e dos elementos menores que 1 milímetro são medidos sobre 2 ou 3 lâminas delgadas e atribuídos a diferença entre o volume total da amostra e o volume dos elementos maiores que 1 milimetro. Tendo-se determinado a densidade de cada espécie de elemento de brecha é fácil de se calcular o peso de cada classe granulométrica em 100 unidades cúbicas de rocha. Este procedimento é adotado para cada classe granulométrica. Tendo-se o peso de cada classe granulométrica para cada espécie de elemento a adição, para cada classe dos pesos de todas as espécies dá o peso total de cada classe (inclusive da matriz), que é, então reduzido a $100 \%$ em relação ao peso total calculado.

Quadro 2 - Características físicas das brechas vulcânicas estudadas (os números de 1 a 19 referem-se à Fig. 6)

\begin{tabular}{|c|c|c|c|c|c|c|c|c|c|}
\hline Curva & Tipo de brecha e proveniência & $\underset{(\mathrm{mm})}{\mathrm{Mz}}$ & $\begin{array}{c}\mathrm{Md} \\
(\mathrm{mm})\end{array}$ & $\begin{array}{l}\text { Moda } \\
(\mathrm{mm})\end{array}$ & $\sigma$ & SK & $\mathrm{Kg}$ & $\begin{array}{l}\text { DMF } \\
(\mathrm{mm})\end{array}$ & $\begin{array}{c}\varepsilon \\
(\%)\end{array}$ \\
\hline 1 & Brecha central cinza de Malavielle & 3,0 & 2,5 & $0,35-0,70$ & 2,52 & 0,02 & 0,70 & 15,0 & 30,3 \\
\hline 2 & Brecha negra de Malavielle & 20,4 & 29,0 & $22,0-45,0$ & 1,40 & 0,60 & 0,99 & - & 20,3 \\
\hline $3^{*}$ & Brecha de explosão de Malavielle & 25,4 & - & - & $-m$ & - & - & - & 11,4 \\
\hline $4^{*}$ & Brecha de borda de Malavielle & 11,0 & - & - & - & - & - & - & 49,4 \\
\hline 5 & Brecha cinza do topo de Mas des Rousses & 5,3 & 6,05 & $5,5-11,0$ & 2,05 & 0,11 & 0,82 & $22,0-25,0$ & 18,6 \\
\hline 6 & Brecha cinza do nível médio de Mas des Rousses & 6,9 & 7,00 & $5,5-11,0$ & 1,56 & 0,03 & 1,10 & - & 24,3 \\
\hline $7^{*}$ & Brecha da base de Mas des Rousses & 7,2 & 5,90 & $11,0-22,0$ & 1,62 & 0,16 & 0,89 & - & 21,5 \\
\hline 8 & Brecha cèntral de Esparou & 10,8 & 11,50 & $11,0-22,0$ & 1,35 & 0,06 & 0,99 & - & 18,9 \\
\hline 9 & Brecha central de Lebrets & 6,25 & 7,44 & $11,0-22,0$ & 1,48 & 0,32 & 1,07 & - & 27,9 \\
\hline 10 & Brecha carbonatada de Lebrets & 4,8 & - & - & - & - & - & $12,0-16,0$ & 26,6 \\
\hline $11^{*}$ & Brecha pelitica vermelha de Lebrets & 8,4 & - & - & - & - & - & - & 12,5 \\
\hline 12 & Brecha marron de Roque Maure sul & 3,95 & 3,10 & $0,7-1,4$ & 1,98 & 0,01 & 0,84 & $12,0 * 16,0$ & 23,2 \\
\hline 13 & Brecha central de Roques & 8,7 & 11,00 & $11,0-22,0$ & 1,53 & 0,38 & 1,30 & - & 18,8 \\
\hline $14^{*}$ & Brecha periférica de Roques & 9,0 & - & - & - & - & - & - & 30,4 \\
\hline 15 & Dique de brecha-Complexo de La Roque & 2,8 & 3,10 & $2,8-11,0$ & 1,53 & 0,10 & 0,85 & 22,0 & 21,7 \\
\hline 16 & Brecha central de Maure & 7,5 & 7,70 & $11,0-22,0$ & 0,61 & 0,1 & 0,92 & 16,0 & 16,3 \\
\hline 17 & Brecha argilosa de Montahut & 1,5 & 1,30 & $5,5-11,0$ & 1,85 & 0,11 & 0,79 & $11,0-13,0$ & 38,2 \\
\hline $18^{*}$ & Brecha aérea de Soumont & 2,98 & 2,80 & $1,4-1,8$ & 1,50 & 0,07 & 0,95 & - & 45,5 \\
\hline 19 & Brecha de fricção de La Roque sul & - & $-m$ & - & - & - & - & - & 22,5 \\
\hline Médias & & 8,08 & - & - & - & - & - & 18,0 & 25,5 \\
\hline
\end{tabular}

\footnotetext{
* Brechas de explosão (externas)

$\mathrm{Mz}$ - média aritmética ou mediana

Md - valor do percentil $\varnothing 50$

Moda - dimensão mais frequiente no histograma de frequência

$\sigma-$ grau de dispersão ("standard deviation")

SK - índice de assimetria ("skewness")

$\mathrm{Kg}$ - indice de angulosidade ou coeficiente de agudes ("kurtosis")

DMF - diâmetro máximo de fluidização

$\varepsilon$ - porosidade
} 
Para que o resultado possa ser apresentado do mesmo modo que os estudos feitos por moagem e peneiramento, é necessário se proceder a uma correção estatística das percentagens. Este tipo de correção não é necessário em uma lâmina delgada porque o resultado procurado é o volume total relativo de uma espécie mineral, enquanto que, no estudo granulométrico, procura-se o peso de uma classe granulométrica. $O$ procedimento de transformação escolhido é o de Greenman (1951) que tem a vantagem de trabalhar em escala logarítmica e dá uma boa precisão final. A descrição detalhada da técnica de medida e correção pode ser encontrada em Biondi (1974). Os resultados obtidos foram tratados estatisticamente segundo os parâmetros de Folk e Ward (1957).

2) Resultados obtidos $\mathrm{O}$ estudo granulométrico, conforme descrito, desenvolveu-se sobre 19 tipos de brecha provenientes de 8 pipes da região de Lodève, sul da França. Os resultados obtidos são transcritos no Quadro 2 e na Fig. 6. Deve-se notar a boa classificação granulométrica mostrada por várias das brechas estudadas. Três outras observações devem ser feitas:

2a) Formações zonadas Entre as formações estudadas, Les Lebrets e Malavielle se destacam pelas suas zonalidades (Figs. 7 e 8). O estudo granulométrico das brechas destas duas formações mostra um aumento gradual do diâmetro médio dos elementos de brecha do centro para as bordas (Fig. 9a e b). Este fato deu origem ao conceito de "brecha central", aparentemente aquela mais evoluída das formações $\mathrm{e}$, por isto, com melhor classificação granulométrica e com elementos de brecha menores e melhor arredondados que as outras brechas do mesmo pipe. Este conceito será discutido posteriormente.

2b) Variação regional do diâmetro médio das brechas centra is Os pipes estudados orientam-se em relação a um eixo de vulcanismo recente denominado eixo do Escandorgue (Fig. 10). Em relação a um ponto deste eixo, o pipe de Montahut, há um aumento gradual da dimensão dos elementos das brechas tipo "central" para norte e para leste (Fig. 11). Montahut se encontra na região do Escandorgue onde o vulcanismo foi mais intenso, e esta variação granulométrica foi interpretada como consequiente da variação de potência do agente erosivo dos elementos de brecha com a distância do centro vulcânico regional. Uma segunda possibilidade de explicação deste fato seria a diminuição das intensidades de implosão de brechiação a partir de Montahut. Estas duas hipóteses serão discutidas. 2c) Índice de classificação ("sorting index") Quanto menor o índice de classificação, melhor classificada é a rocha. A maioria das brechas estudadas (Fig. 6) são medianamente classificadas e outras são mal classificadas. As explicações serão consideradas após o desenvolvimento de alguns estudos sobre o processo de fluidização.

3) Teoria de fluidizaşão 3a) $\mathrm{O}$ processo de fluidização Se um fluido percola a baixa velocidade, através de uma camada formada por qualquer material sólido granulado, haverá uma pequena diferença de pressão entre a base e o topo da camada. Quando a velocidade de percolação do fluido for aumentada gradualmente, a diferença de pressão atingirá um ponto de equilíbrio no qual o peso da camada percolada é igual à diferença de pressão entre o topo e a base da camada multiplicada pela superficie de uma secção da coluna que contém a camada (Ponto B, Fig. 12). Esta situação pode ser descrita pela relação (para notação das equações consultar sempre o Quadro 3):

$$
P=\frac{V}{A} \quad(1-\varepsilon \mathrm{m}) \quad(\rho \mathrm{s}-\rho)
$$

Quadro 3-Simbologia e unidades usadas nas equações

\begin{tabular}{|c|c|c|}
\hline Sinal & Definição & Unidade \\
\hline$\Delta \mathbf{P}$ & Diferença de pressão & lb/pés ${ }^{3}$ \\
\hline$\Delta \mathrm{p}$ & Gradiente de pressão & $\mathrm{lb} /$ pés $^{3} \cdot$ pés \\
\hline$V$ & $\begin{array}{l}\text { Volume de material contido em uma } \\
\text { coluna }\end{array}$ & pés $^{3}$ \\
\hline$A$ & Superficie da secção de uma coluna & pés ${ }^{2}$ \\
\hline$L$ & Altura da camada não dilatada & pés \\
\hline $\mathrm{gm}$ & $\begin{array}{l}\text { Vazios ou porosidade mínima de } \\
\text { fluidização }\end{array}$ & \\
\hline$\varepsilon$ & $\begin{array}{l}\text { Porosidade ou proporção de vazios } \\
\text { em uma coluna }\end{array}$ & \\
\hline$\rho \mathrm{s}$ & Densidade de um sólido (partículas) & $\mathrm{lb} / \mathrm{pés}^{3}$ \\
\hline$\rho$ & Densidade do fluido & lb/pés ${ }^{3}$ \\
\hline$D$ p & Diâmetro efetivo das partículas & pés \\
\hline de & Diâmetro de um canal equivalente & pés \\
\hline & seção do recipiente & $\mathrm{lb} /$ pés $^{3} \cdot \mathrm{h}$ \\
\hline$u$ & $\begin{array}{l}\text { Velocidade calculada no recipiente } \\
\text { vazio }\end{array}$ & pés/s \\
\hline$u e$ & Velocidade nos poros da camada & pés/s \\
\hline$\eta$ & Viscosidade do fluido & lb/h · pés \\
\hline$\dot{K}$ & Constante & - \\
\hline$r$ & Raio hidráulico de Leva & pés \\
\hline$\lambda$ & Fator de forma de Leva & - \\
\hline$g$ & $\begin{array}{l}\text { Constante de aceleração devida a } \\
\text { gravidade }\end{array}$ & $4,18 \times 10^{8}$ pés $/$ hora $^{2}$ \\
\hline$D \mathrm{t}$ & Diâmetro de uma coluna & pés \\
\hline
\end{tabular}



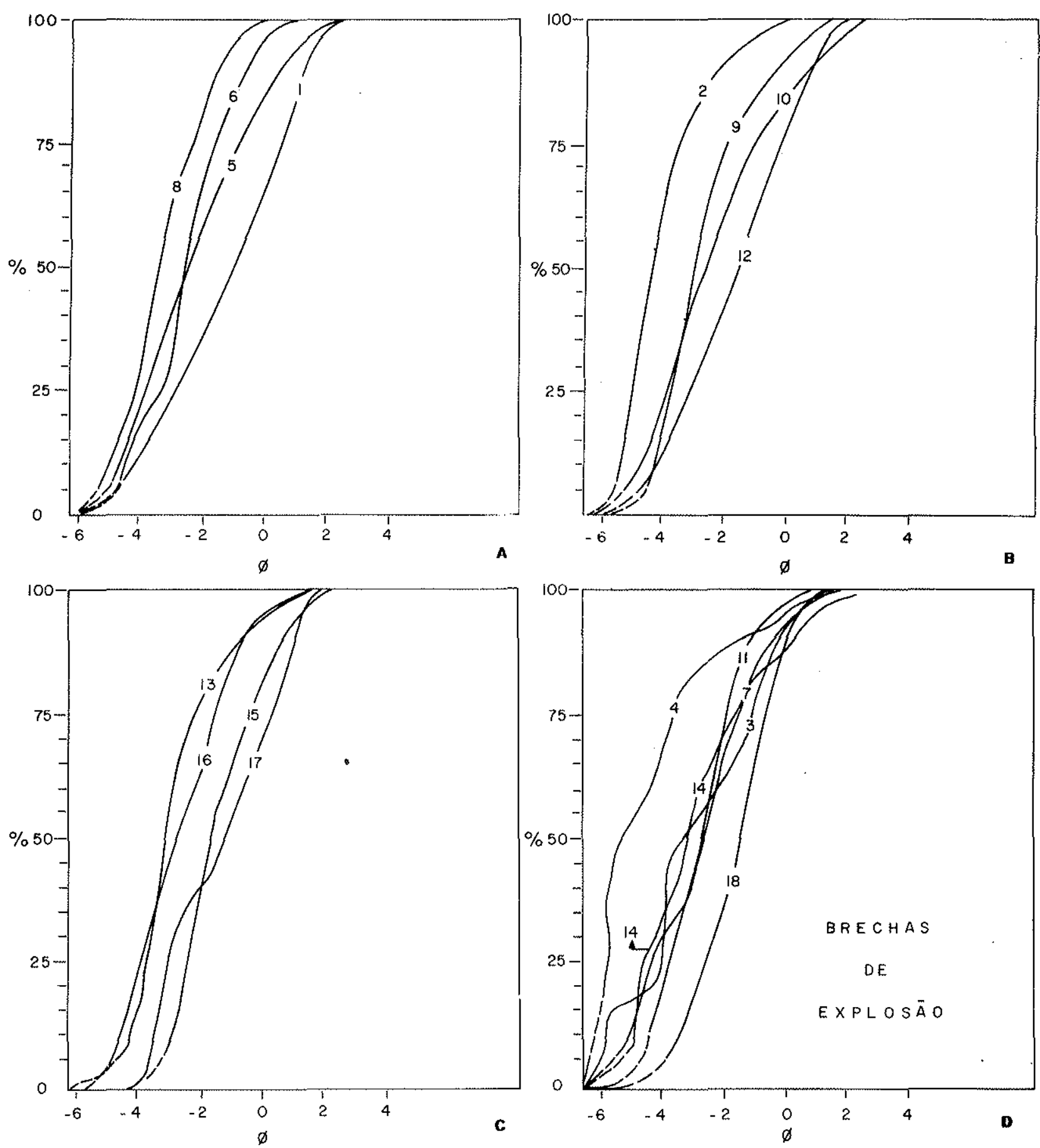

Figura 6 - Curvas cumulativas de distribuição granulométrica das brechas estudadas. Em D. estão as curvas correspondentes as brechas de explosão. Os números referem-se ao quadro 2

Aumentando-se gradualmente a velocidade de percolação, a camada se dilata, e a percentagem de vazios aumenta, mas a diferença de pressão é constante. A uma velocidade precisa, a camada estará dilatada o suficiente para que cada partícula esteja a uma distância de suas vizinhas que permita a sua vibração. Esta camada estará, então, em fluidização. A Eq. (7) define o inicio do processo. Um aumento da velocidade de percolação poderá originar um movimento de conveç̧ão (Leva et al., 1948), além do movimento de vibração.

Iniciada a fluidização, dois fenômenos podem ocorrer. Para altas velocidades de percolação, o fluido pode formar bolhas que forçarão passagem para cima. É o fenômeno denominado de efervescência (slugging). Pode, também, ocorrer a formação 


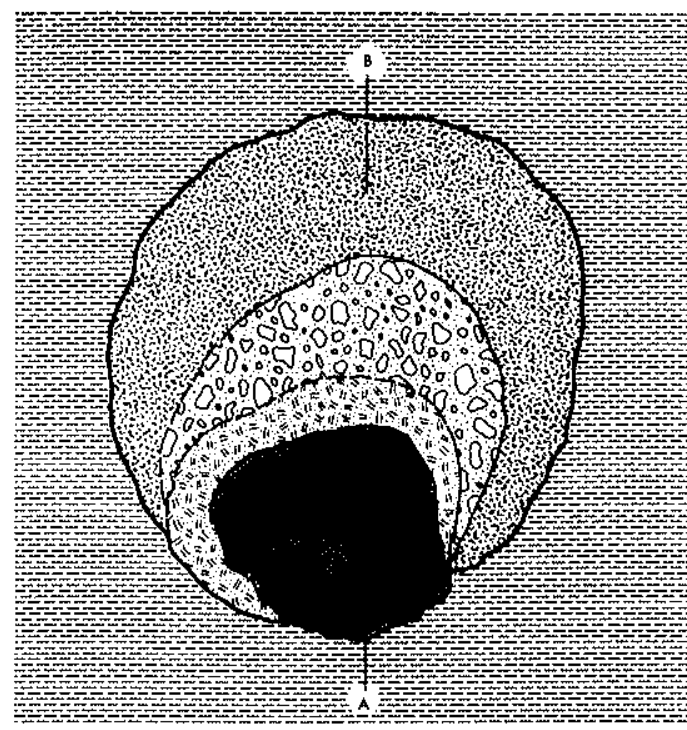

Bosollo macifo

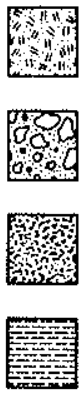

Microbrecha a cimento basaltico

Brocho o cimento carbonatodo

Brecho vermetino a elementos peliticos

Peliros varmellos do Permiono

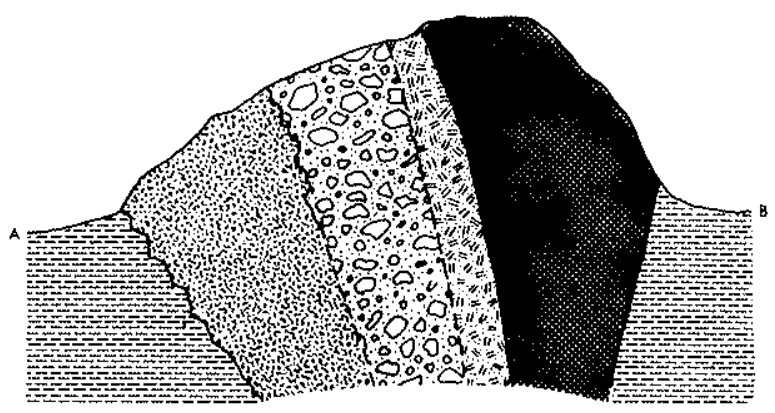

LES LEBRETS

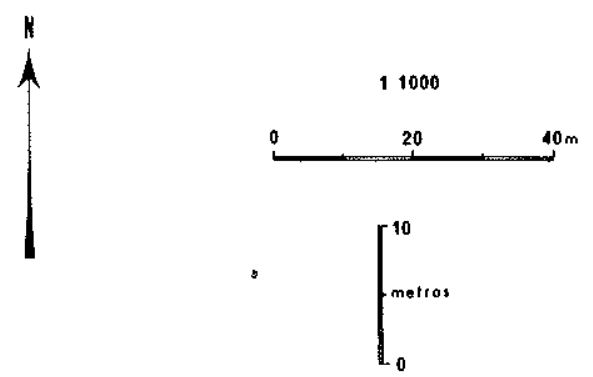

Figura 7- Mapa e secção geológica do pipe Les Lebrets. Notar a distribuição concêntrica dos diversos tipos de brecha. No caso, a brecha "central" (mais evoluida) é a de cimento basáltico

de canais devido ao fluido percolar através da camada. $\mathrm{O}$ acanalamento (channeling) pode se formar mesmo com baixas velocidades de percolação, quando as partículas forem muito finas ou se a camada estiver umedecida.

Entre os dois tipos de fluidizações industriais, a estática e a contínua, somente a fluidização estática, a mais importante, será vista em detalhe, pois na fluidização contínua as leis clássicas de hidrodinâmica restam válidas.

3b) Equacionamento da fluidização Em hidrodinâmica o gradiente de pressão de um fluido que atravessa um tubo é:

$$
\Delta \mathrm{p}=\frac{\Delta \mathrm{p}}{L}=\frac{\rho u^{2}}{g D t} f\left\lceil\frac{(D t u \rho)}{\eta}\right\rceil
$$

$$
\begin{aligned}
& f=\text { função de } \\
& =\frac{\rho u^{2}}{g D t} K^{\prime}\left[\frac{(D t u \rho)}{\eta}\right]^{n-2} \\
& =\frac{K^{\prime}}{g} \cdot \frac{\eta^{2-n}}{\rho^{1-n}} \cdot u^{n} \cdot D t^{n-3}
\end{aligned}
$$

Adotando o raciocínio de Carman (1937), Leva (1947) introduz modificações para que a Eq. (8) seja válida para um fluxo atravessando uma camada de composição granular. A velocidade verdadeira de percolação do fluido através dos poros é $u$ e $=u / \varepsilon$. Aceitando a dimensão dos poros da camada como sendo comparável ao diâmetro das partículas, define-se o raio hidráulico de Leva et al., (1948):

$$
r=\frac{\frac{\varepsilon}{1-\varepsilon} \cdot V}{A i}=\frac{V \varepsilon}{(1-\varepsilon) i A}
$$




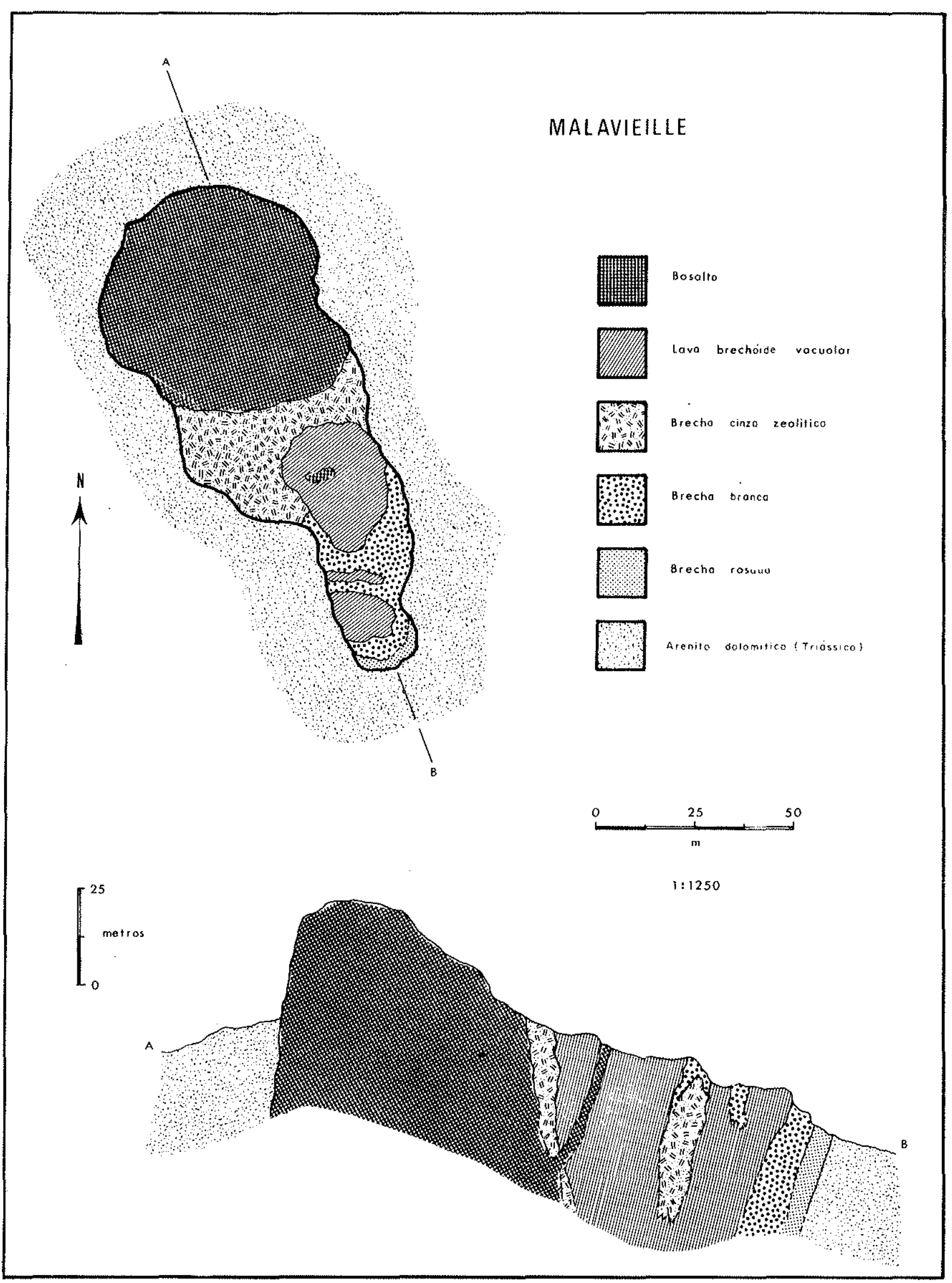

Figura 8 - Mapa e seç̧ão geológica do pipe de Malavielle. A simetria de distribuição das brechas é menos perceptivel. A brecha mais evoluída, tipo brecha "central", é aquela de cor cinza e matriz zeolítica 

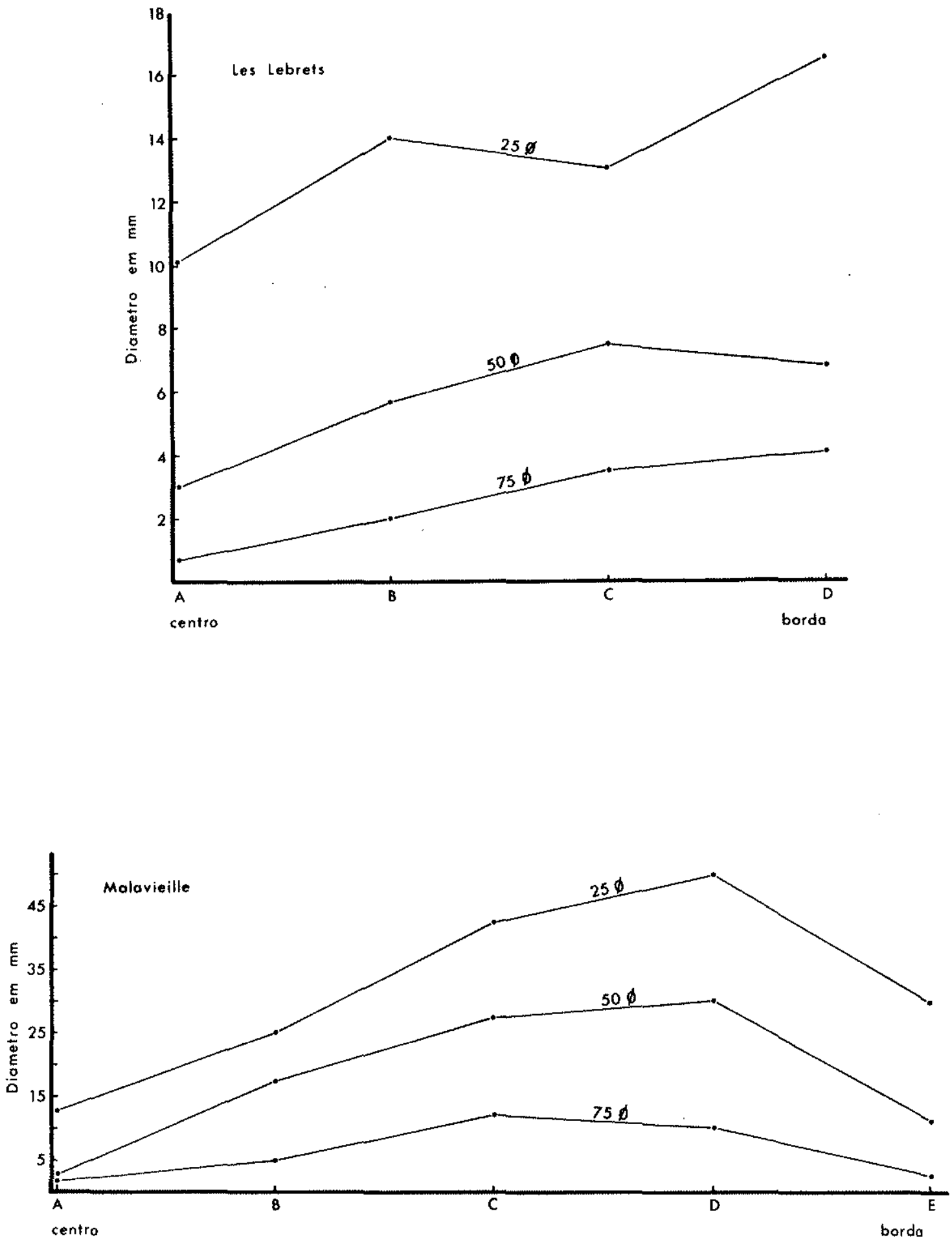

Figura 9-Variação granulométrica das brechas dos pipes de Les Lebrets (a) e Malavielle (b). Notar o aumento gradativo da granulometria do centro para as bordas, (ver Figs. 7 e 8). As brechas ditas "centrais". são sempre as mais evoluídas por serem as mais fluidizadas 


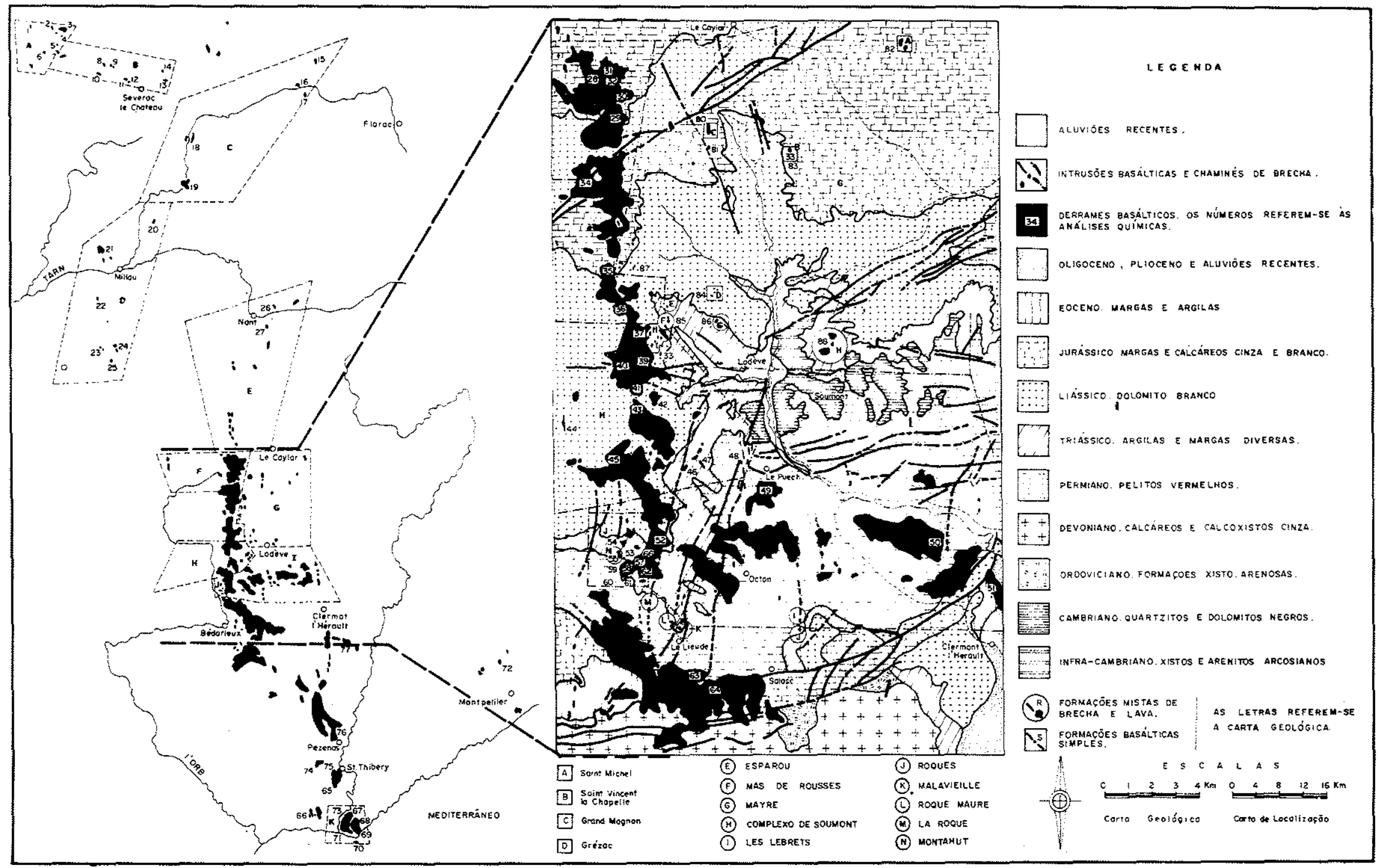




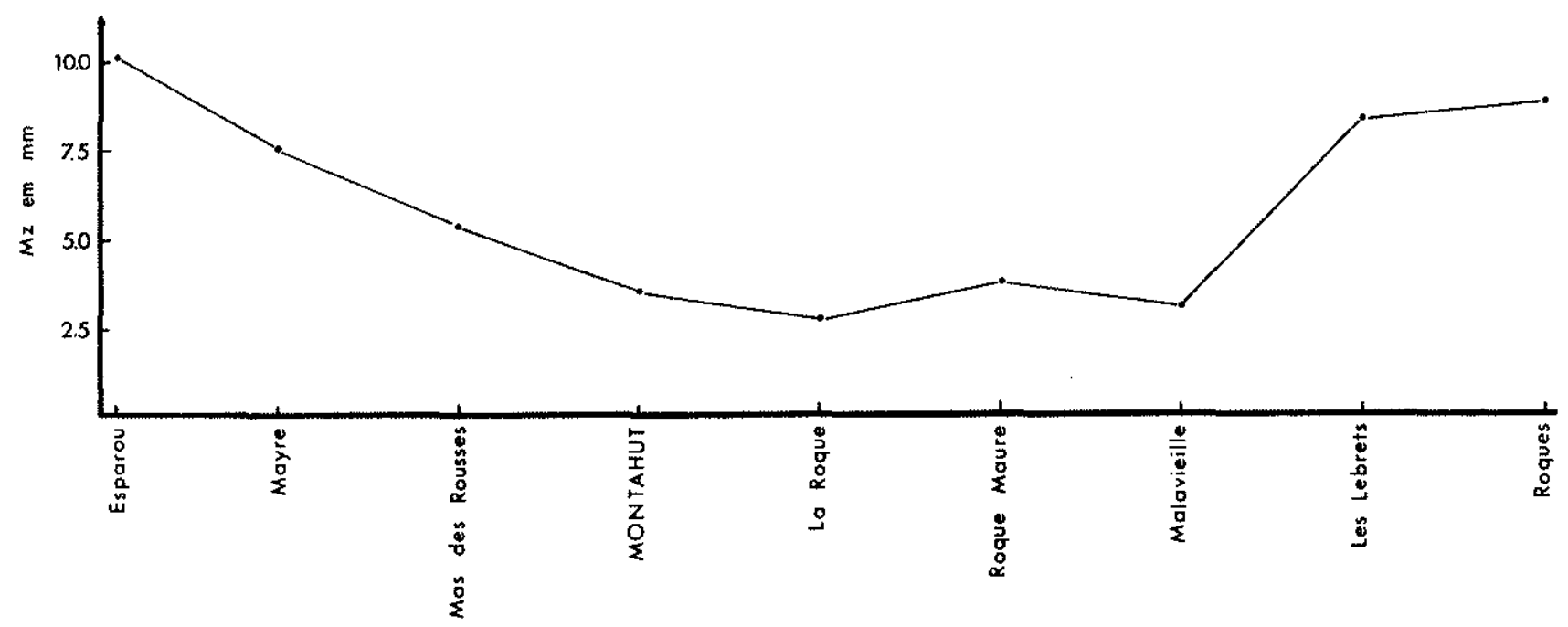

Figura 11 - Variação do diâmetro médio $(\mathrm{Mz})$ dos elementos de brecha dos pipes estudados em relação à distância até o pipe de Montahut (ver Fig. 10)

No caso de uma camada de composição granular, $r$ é o equivalente ao diâmetro de um tubo, o que permite substituir $D t$ por $r$ em (8). Considerando-se $u$ e $=u / \varepsilon$, deriva-se:

$\Delta p=\frac{K^{\prime}}{g} \cdot\left[\frac{\eta^{2-n}}{\rho^{1-n}}\right] \cdot\left[\frac{u}{\varepsilon}\right]^{n} \cdot\left[\frac{V \varepsilon}{A \lambda(1-\varepsilon)}\right]^{n-3}$

Simplifica-se (9), considerando-se uma camada de esferas de modo que $V / A=d / 6 \mathrm{e}$, considerando-se ainda $\rho u=G$, a Eq. (9) transformar-se-á :

$\Delta p=\frac{K^{\prime}}{g} \cdot\left[\frac{d G}{\eta}\right]^{n} \cdot \frac{\eta^{2}}{\rho} \cdot \frac{\lambda^{3-n}}{d^{3}} \cdot \frac{(1-\varepsilon)^{3-n}}{\varepsilon^{3}}$

O expoente $n$ é denominado "coeficiente de estado de fluxo" podendo ter qualquer valor entre $n=1$, para um fluxo totalmente laminar, e $n=2$ para as condições máximas de turbulência. Em cada caso $n$ deverá ser medido experimentalmente. A Fig. 13 permite a avaliação de $n$ em função de $G$.

A Eq. (10) é válida para a fase de dilatação da camada (AB, Fig. 12), permitindo calcular o gradiente de pressão de um fluido gasoso que atravessa uma camada granular. $O$ começo do estado de fluidização (ponto B, Fig. 12) é marcado pela suspensão e vibração das partículas da camada, o que induz a existência de um fator de fricção entre o fluido e as partículas. Leva et al., (1948) definiram o fator de frição $f \mathrm{~F}$, que é inversamente proporcional à própria fricção, podendo ser definido por:

$$
f \mathrm{~F}=\frac{\Delta P D \mathrm{p} \rho g \varepsilon^{3}}{2 G^{2} L(1-\varepsilon)^{2}}
$$

$\mathrm{Na}$ região de fluxo $(R \mathrm{e}<10), f \mathrm{~F}=C / R \mathrm{e}(\mathrm{Ftg}$. 13) onde $C$ é uma constante. Ainda da Fig. 13, para $R \mathrm{e}=1$, tem-se $f \mathrm{~F}=100$, portanto,

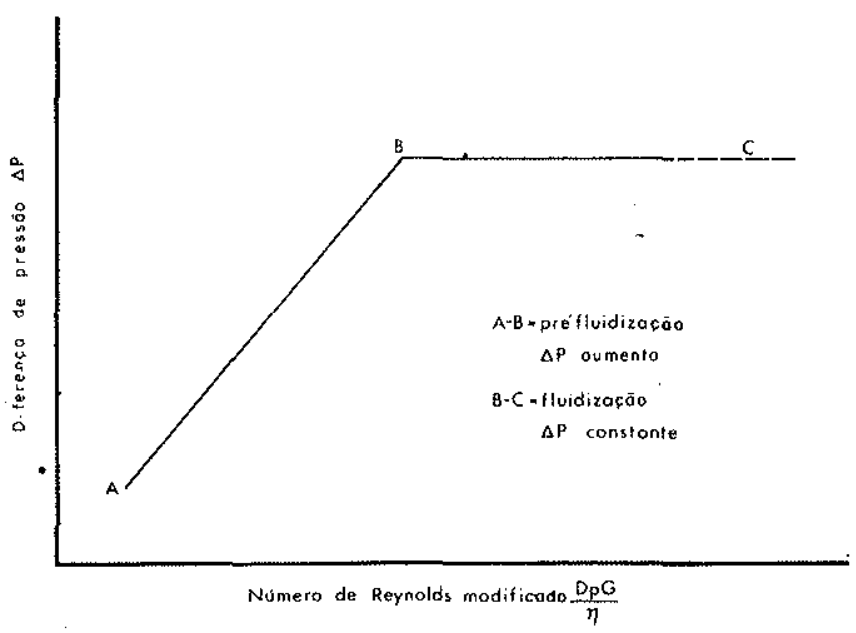

Figura 12 - Gráfico ilustrativo das. fases de um processo de fluidização.

$$
f \mathrm{~F}=\frac{C}{R \mathrm{e}}=\frac{100}{R \mathrm{e}}=\frac{D p G}{\eta}
$$

Combinando-se (11) e (12) com (10) e encontrando-se a solução para $\Delta \mathrm{p}$ :

$$
\Delta \mathrm{p} L=\Delta \mathrm{P}=\frac{200 G \eta L \lambda^{2}(1-\varepsilon)^{2}}{D \mathrm{p} \rho g \varepsilon^{3}}
$$

que permite o cálculo da queda de pressão que ocorre em fluxos com número de Reynold entre $10^{-3}$ e 10 . $\mathrm{Na} z o n a$ transicional, onde Re varia entre 10 e 100 recomenda-se :

$$
\Delta \mathbf{P}=\frac{2 f \mathrm{~F} G^{2 n} L \lambda^{3-n}\left(1^{\circ}-\varepsilon\right)^{3-\mathrm{n}}}{D \mathrm{p} g \rho \varepsilon^{3}}
$$

onde $f \mathrm{~F}$ e $n$ dependem de $R \mathrm{e}$, avaliados na Fig. 12. 


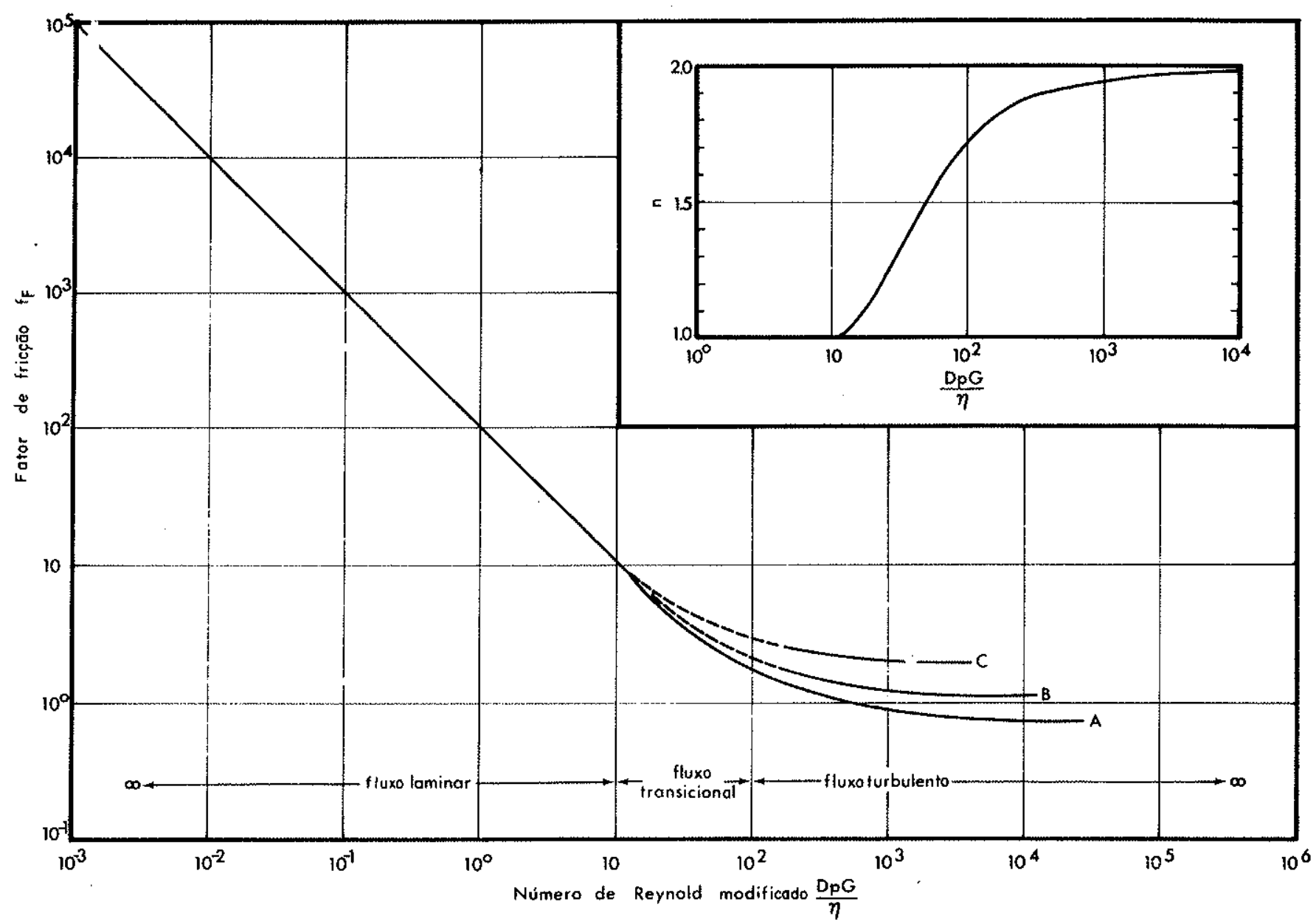

Figura 13 - Gráficos para a determinação de $f \mathrm{~F}$ e $n$ em função do número de Reynold (modificado, Leva et al, 1948). Coordenadas bilogarítmicas

Combinando as equações (7) e (13) e encontrando-se a solução para $G$, obter-se-á uma equação que define a velocidade de massa necessária para iniciar a fluidização em uma camada de composição granular, sob condições de fluxo laminar $(R<10)$.

$$
G=\frac{0,005 D \mathrm{p}^{2} \varepsilon \mathrm{m}^{3}(\rho \mathrm{s}-\rho) \rho g}{\lambda^{2}(1-\varepsilon \mathrm{m}) \eta}
$$

O mesmo raciocínio sendo feito para (14), após rearranjo, resulta $\mathrm{em}$ :

$$
G^{2}=\frac{D \operatorname{pg} \rho(\rho \mathrm{s}-\rho) \varepsilon \mathrm{m}^{3}}{2 f \mathrm{~F} \lambda^{3-n}(1-\varepsilon \mathrm{m})^{2-n}}
$$

Válido para a zona de fluxo transicional $(10<R$ e $<$ $<100$ ). As equações (15) e (16) dão $G$, velocidade de massa. A determinação de $n$, velocidade linear, exige a divisão de $G$ pela densidade do fluido percolante.

4) Fluidização na natureza Considerando-se o modelo de implosão-fluidização, as equações deduzidas para a fase de fluidização e os dados obtidos no estudo granulométrico, é possível se quantificar as observações feitas no campo. A equação de base sendo (16), é necessário que seus termos sejam definidos:

4a) Definição dos elementos da equação 1 - Densidade do fluido e dos elementos (partículas da camada) e viscosidade do fluido $(\rho \mathrm{s}, \rho$ e $\eta)$ :

Segundo o modelo proposto, o principal agente de fluidização é o vapor d'água. Kennedy e Nordlie (1968) e Wilshire (1961) forneceram indicações segundo as quais a temperatura de mise-en-place das brechas de pipes não deve ultrapassar $200^{\circ} \mathrm{C}$. Após a fase implosiva, a descompressão deve proporcionar uma queda brusca na temperatura do vapor d'água, que dificilmente proporcionará a formação de um ambiente cuja temperatura ultrapasse de muito os $100^{\circ} \mathrm{C}$. A densidade do vapor d'água varia de $0,0014 \ell \mathrm{b} /$ pé cúbico a $25^{\circ} \mathrm{C}$ até $0,727 \ell \mathrm{b} /$ pé cúbico a $220^{\circ} \mathrm{C}$, sendo de $0,037 \mathrm{lb} /$ pé cúbico a $100^{\circ} \mathrm{C}$. As velocidades mínimas de fluidização $(G, \mathrm{Eq} .16)$ variam proporcionalmente à densidade do fluido. Nos cálculos a seguir, o fluido será considerado como uma mistura de vapor d' água $+\mathrm{CO}_{2}$ a $100^{\circ} \mathrm{C}$, com den- 
sidade de $0,04 \ell \mathrm{lb} /$ pé cúbico $\left(8,4 \times 10^{-4} \mathrm{~g} / \mathrm{cm}^{3}\right)$ e viscosidade de 125 micropoises. A densidade do fluido deverá variar com a razão vapor $/ \mathrm{CO}_{2}$ e com o aumento de finos originados da desagregação dos elementos de brecha, à medida que as brechas evoluam por fluidização.

A densidade média dos elementos de brechas varia com a proporção de elementos vulcânicos e sedimentares presentes. Será considerado o valor de $156 \ell \mathrm{b} /$ pé cúbico $\left(2,5 \mathrm{~g} / \mathrm{cm}^{3}\right)$ quando os elementos sedimentares predominarem e $168 \ell \mathrm{b} /$ pé cúbico $\left(2,7 \mathrm{~g} / \mathrm{cm}^{3}\right)$ quando a maior quantidade for de elementos vulcânicos.

2 - Porosidade $(\mathrm{mm}): \quad$ O sistema de fluidização é imobilizado quando a pressão de gás não é mais suficiente para fazer vibrar os elementos de brecha. Neste ponto (B, Fig. 12), os elementos serão imobilizados preservando uma certa porosidade. Esta porosidade corresponde ao valor encontrado quando foi medida a percentagem volumétrica de matriz nas brechas (Quadro 2).

3 - Fator de forma $(\lambda)$ : Variável entre 1,0 para uma esfera e 2,0 para elementos sem nenhum arredondamento. $\mathrm{O}$ valor 1,3 será adotado como constante, visto que geralmente os elementos são bastante bem arredondados.

4 - Diâmetro efetivo $(\mathrm{Dp})$ : Será considerado como igual a mediana $(\mathrm{Mz})$, determinada segundo a equação de Folk e Ward (1957). Ver o Quadro 2.

5 - Fator de fricção $(f \mathrm{~F})$ e de estado de fluxo $(n)$ : Estes fatores são avaliados dos gráfícos da Fig. 12. Em condições naturais, certamente haverá um fluxo sob condições de turbulência próximas de $R \mathrm{e}=100$. Note-se que a equação (11) define $f \mathrm{~F}$ como inversamente proporcional a $L$, altura da camada. Portanto $G$ (Eq. 16) é diretamente proporcional a $L$, o que mostra que quanto maior for a camada a fluidizar, mais forte deve ser o fluxo gasoso inicial. A quantidade de vapor disponivel depende da quantidade de brecha originada por implosão. A altura da coluna de brecha é função direta da velocidade de ascensão da lava, geradora das condições de descompressão necessária. a implosão (Fig. 5). Quanto mais distante for um pipe do centro de origem do magma, maior será o caminho percorrido pela lava, que deverá, portanto, ter uma menor velocidade de ascensão no fím do caminho e que originará uma coluna de brecha pouco importante. Isto explicaria que nas formações vulcânicas distantes de Montahut (Figs. 10 e 11) os elementos de brecha sejam, em média, maiores. Nestes pipes haveria um período de fluidização mais curto e os elementos seriam menos erodidos e maiores em diâmetro médio. Notar ainda que uma descompressão menos violenta, originada por uma lava a menor velocidade de ascensão, daria origem a uma explosão também menos violenta com o aparecimento de elementos grandes, menos desagregados. Estes dois fatores devem agir concomitantemente.

4b) Fluidização em um pipe Logo após a fase implosiva, o fluido liberado é uma mistura de vapor d'água e $\mathrm{CO}_{2}$. Inicialmente, todas as brechas são originadas da implosão. Os cálculos, por isso, serão feitos com as medidas feitas nas brechas de explosão do Quadro 2 (marcadas com *). Os valores da Eq. 16 serão:

$$
\begin{aligned}
D \mathrm{p} & =0,035 \mathrm{pd}(10,9 \mathrm{~mm}) \\
\rho & =0,04 \ell \mathrm{b} / \text { pé cúbico }\left(8,4 \times 10^{-4} \mathrm{~g} / \mathrm{cm}^{3}\right) \\
\rho \mathrm{s} & =156 \ell \mathrm{b} / \text { pé cúbico }\left(2,5 \mathrm{~g} / \mathrm{cm}^{3}\right) \\
\varepsilon & =0,22 \\
f \mathrm{~F} & =1,1(R \mathrm{e}=100) \\
n & =1,7 \\
\lambda & =1,7 \\
g & =4,18 \times 10^{8} \text { pés } / \mathrm{h}^{2}\left(981 \mathrm{~cm} / \mathrm{s}^{2}\right)
\end{aligned}
$$

Estes valores em (16) dão $G=696,5 \mathrm{\ell b} / \mathrm{pé}^{2} / \mathrm{h}$ ou $2869,6 \mathrm{~kg} / \mathrm{m}^{2} / \mathrm{h}$, resultando em velocidade linear $V=4,9$ pés $/ \mathrm{s}=1,6 \mathrm{~m} / \mathrm{s}=5,8 \mathrm{~km} / \mathrm{h}$. A velocidade de fluxo necessária para iniciar a fluidização em uma coluna de brecha é relativamente fraca, isto sendo devido a forte densidade do vapor d'água superaquecido.

A velocidade de fluxo necessária para iniciar a fluidização foi calculada para todas as brechas "tipo central" dos pipes (Quadro 4). Constata-se ser necessária uma maior velocidade para iniciar a fluidização em uma brecha de explosão $(5,8 \mathrm{~km} / \mathrm{h}$ calculado acima) do que para fluidizar uma brecha central bem evoluída. Pode-se, portanto, prever uma diminuição na velocidade mínima de fluidização à medida que o sistema evolui. Quanto maior o tempo que uma formação tenha sido fluidizada, mais os elementos de brecha serão arredondados e selecionados e menor será a velocidade de fluxo necessária para fluidizá-la. Quando o sistema se extinguir, serão guardadas as características que portava nos últimos momentos de fluidização, ou seja, o arredondamento dos ele-

Quadro 4 - Velocidade mínima de fluidização dos pipes estudados (brechas centrais)

\begin{tabular}{l|c|c|c}
\hline \multicolumn{1}{c|}{ Pipe } & $\begin{array}{c}G \\
\text { lb/pés }\end{array}$ & $\begin{array}{c}V \\
\mathrm{~m} / \mathrm{s}\end{array}$ & $\begin{array}{c}V \\
\mathrm{~km} / \mathrm{h}\end{array}$ \\
\hline Mas des Rousses & 625,0 & 1,43 & 5,15 \\
Malavielle & 807,0 & 1,85 & 6,66 \\
Montahut & 512,0 & 1,17 & 4,21 \\
Mayre & 389,0 & 0,89 & 3,20 \\
Dique de la Roque & 422,0 & 0,96 & 3,46 \\
Les Lebrets & 714,0 & 1,63 & 5,87 \\
Roque Maure & 561,0 & 1,28 & 4,61 \\
Roques & 570,0 & 1,31 & 4,72 \\
Esparou & 649,0 & 1,49 & 5,36 \\
\hline
\end{tabular}




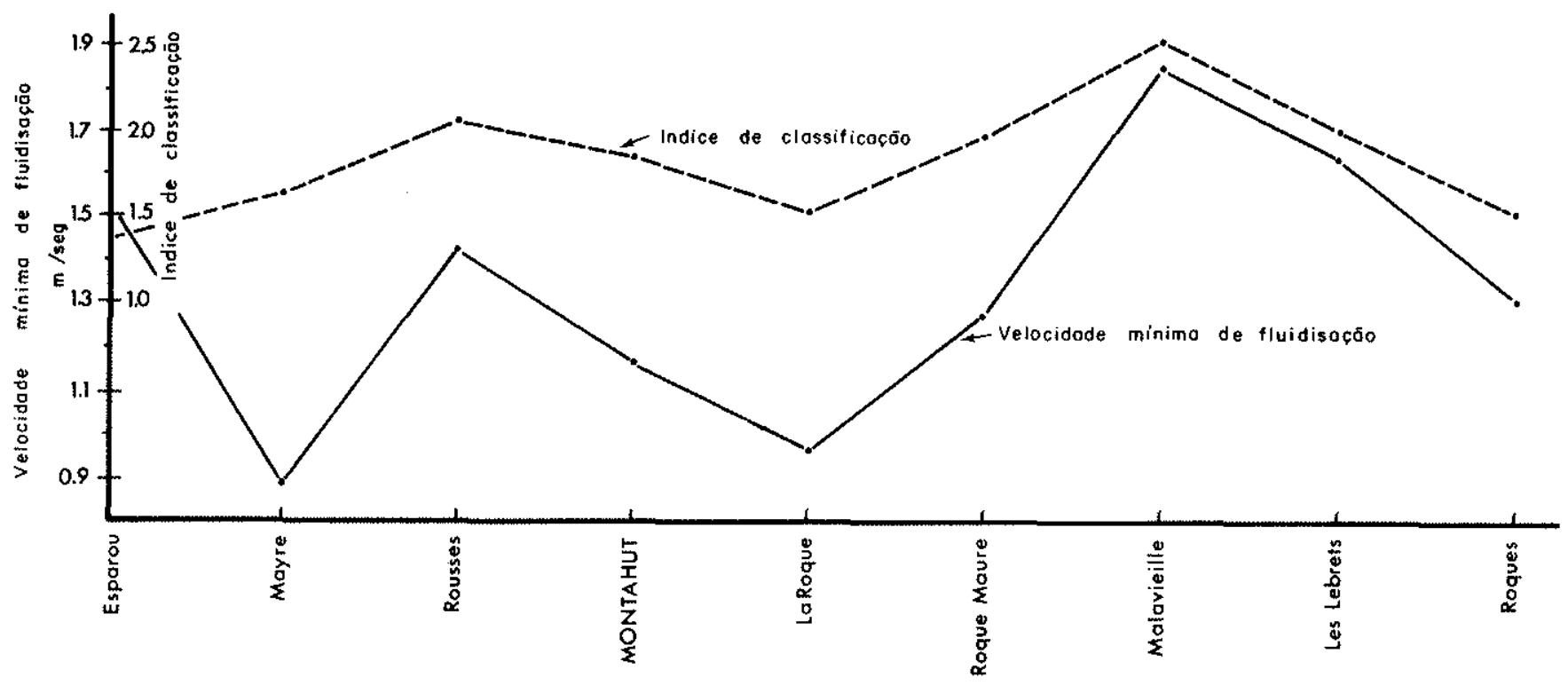

Figura 14 - Comparação entre as velocidades mínimas de fluidização e o índice de classificação das brechas "centrais" dos pipes estudados (Fig. 9 a e b, ponto A). Notar a coincidência no comportamento de ambas as curvas, à exceção do ponto correspondente ao pipe de Esparou (pipe "cego")

mentos de brecha, a boa classificação das brechas, a porosidade, e outros valores transcritos no Quadro 2. As menores velocidades medidas indicam os sistemas mais evoluídos. Se a evolução das brechas se fez por fluidização, aquelas onde foram medidas as menores velocidades de fluidização devem ser as melhores classificadas, mostrando os menores índices de classificação. Na Fig. 14, compara-se o índice de classificação das brechas "tipo central" dos pipes com a velocidade necessária para fluidizá-las. A única discrepância, a brecha do pipe de Esparou, seria explicada pelo fato desta formação não ter alcançado a superficie (pipe cego, portanto, nada ou pouco fluidizado).

4c) Os limites de velocidade de fluxo O elemento de brecha de maior diâmetro que tenha sido fluidizado por um fluxo gasoso é um bom indicador da velocidade máxima de percolação do fluido (Eqs. 15 ou 16). Este diâmetro será denominado Diâmetro Máximo de Fluidização (DMF, Quadro 2). Qualquer elemento maior que DMF não será fluidizado, devendo se dirigir para a base do sistema gás-sólido. A evolução do sistema, faz-se pelo desgaste por fricção entre os elementos das diversas classes granulométricas, havendo, portanto, a partir do desgaste dos elementos de uma determinada classe, o aumento da quantidade de elementos das classes inferiores. Somente os elementos do tipo DMF serão destruídos mas não receberão elementos de classes superiores, visto que estas classes não serão fluidizadas. Em um sistema bem evoluído, portanto, o DMF deve ser a classe de menor representação em número de elementos. Tanto as classes superiores, de maior diâmetro, quanto as inferiores terão maior participação numérica no sistema total.
Em um gráfico onde seja lançada a percentagem de volume da brecha ocupado pelas diversas classes granulométricas contra a quantidade de elementos de cada classe, deve ter um mínimo, correspondente à classe que contém o elemento que $\mathrm{tcm}$ tendência a desaparecer, o DMF (Fig. 15). Este tipo de gráfico foi elaborado para as brechas com maiores evidências de terem evoluído por fluidização. Os resultados constam no Quadro 2 e os dois casos mais típicos são mostrados na Fig. 15. No pipe de Mas des Rousses, há um ponto mínimo de inversão, entre $12-13 \mathrm{~mm}$ que deve, portanto, corresponder ao DMF. Para o dique de brecha de La Roque (Fig. 10) não há ponto de inversão, deduzindo-se que o fluxo gasoso foi suficientemente possante para destruir por fluidização todos os elementos presentes. Neste caso o DMF não existe.

Obtendo-se o maior diâmetro que um fluxo pode fluidizar, a Eq. 16 permite o cálculo da maior velocidade de percolação do sistema desde que seja admitida a constância dos outros valores da equação. $O$ cálculo foi feito considerando-se uma camada constituída unicamente de elementos de diâmetro igual a DMF, o que imporá um erro por excesso. Não é certo que a Eq. 16 seja válida para um $\mathrm{Dp}$ desta importância. $O$ cálculo feito com a média de todos DMF calculados resulta em $G=1548,1 \ell \mathrm{b} / \mathrm{pé}^{2} \times$ $\times \mathrm{h} \times(4,12)=6378,2 \mathrm{~kg} / \mathrm{m}^{2} / \mathrm{h}$. Portanto $V=10,75$ pés $/ \mathrm{s}=3,55 \mathrm{~m} / \mathrm{s}=12,8 \mathrm{~km} / \mathrm{h}$.

As velocidades de fluxo para iniciar a fluidização de um pipe serão, portanto, variáveis entre $0,89 \mathrm{~m} / \mathrm{s}$ $(3,2 \mathrm{~km} / \mathrm{h})$ e $3,55 \mathrm{~m} / \mathrm{s}(12,8 \mathrm{~km})$ (Quadro 4).

4d) Volume de fluido e duração do estado de fluidização Segundo o modelo de implosão-fluidização, 


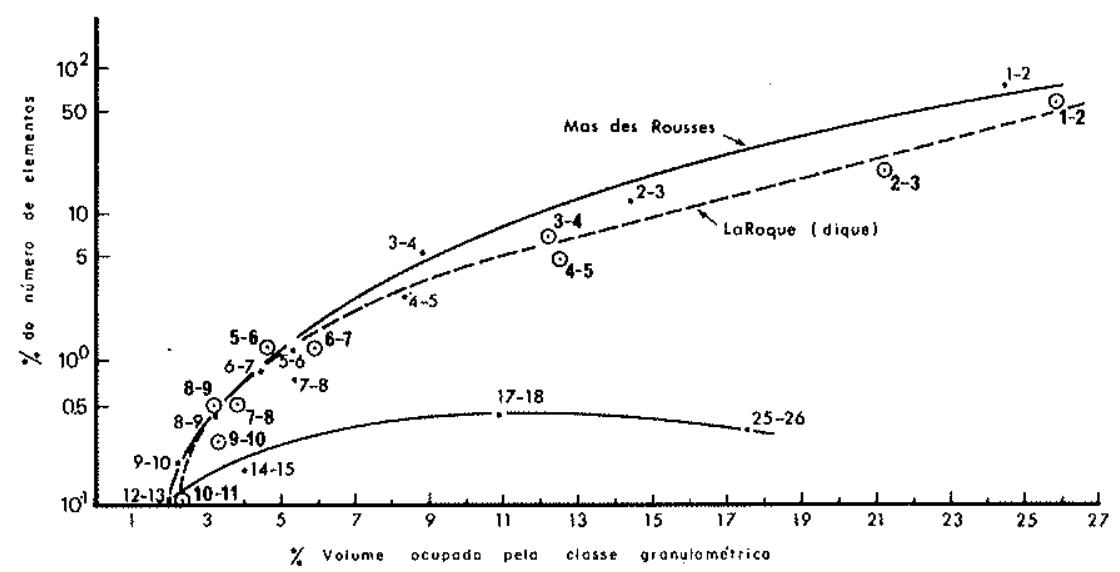

Figura 15 - Curva de determinação do DMF (Diâmetro Máximo de Fluidização). O ponto de inversão corresponde ao DMF da brecha estudada. Caso inexista uma inversão, o fluxo foi possante, o suficiente para fluidizar todos os elementos da brecha (brecha do dique de La Roque, por exemplo)

o principal agente de fluidização é o vapor d'água. O Quedro 5 mostra o volume d'água contido antes da impıosão, entre o contato da coluna de lava e a isoterma de $150^{\circ} \mathrm{C}$. A este volume seria necessário adicionar toda a água aquecida entre as isotermas de $100^{\circ} \mathrm{C}$ e $150^{\circ} \mathrm{C}$ e, ainda, todo o $\mathrm{CO}_{2}$ de origem magmática disponivel no sistema. A fluidização deve começar quando o fluxo tiver uma velocidade próxima de $2800 \mathrm{~kg} / \mathrm{m}^{2} / \mathrm{h}$ (brecha de explosão) reduzindo-se, com a evolução do sistema, para valores de cerca de $2000 \mathrm{~kg} / \mathrm{m}^{2} / \mathrm{h}$ (Quadro 4). Os cálculos foram feitos, considerando-se uma velocidade média de $2400 \mathrm{~kg} / \mathrm{m}^{2} / \mathrm{h}$. O modelo considerado é idêntico ao da Fig. 1, quando a coluna de lava tiver $60 \mathrm{~m}$ de diâmetro. Como as isotermas desaparecem em superfície e se alargam em profundidade até $108 \mathrm{~m}$ de diâmetro total $(60 \mathrm{~m}$ de basalto $+48 \mathrm{~m}$ até as isotermas de $150^{\circ} \mathrm{C}$ ) será considerado um diâmetro médio de $80 \mathrm{~m}$ após a implosão, o que corresponde a uma secção de $5000 \mathrm{~m}^{2}$. Será admitido que esta coluna será inteira e uniformemente fluidizada e que somente a metade da água existente será disponivel para a fluidização, ou seja 131,5 × $10^{6}$ litros (Quadro 5).

Um fluxo com velocidade média de $2400 \mathrm{~kg} / \mathrm{m}^{2} / \mathrm{h}$ fluidizando uma secção de $5000 \mathrm{~m}^{2}$ dá uma vazão de $12,0 \times 10^{6} \ell / \mathrm{h}$ que, originada dos $131,5 \times 10^{6} \mathrm{li}-$ tros disponiveis, permite um total de 10,9 horas de fluidização contínua.

Em um pipe a fluidização se faz sempre por zonas, a começar por aqueles onde a permeabilidade é maior, progredindo de modo centrífugo a partir destas zonas. Entre os pipes estudados nunca foi visto em afloramento uma superficie de brecha de fluidização com mais de $5000 \mathrm{~m}^{2}$. Evidentemente, a velocidade de percolação poderá ultrapassar largamente os $3,55 \mathrm{~m} / \mathrm{s}$ acima calculados quando a secção de percolação for menor.
Quadro 5 - Volume d'água contido em uma coluna de brecha formada a partir de uma coluna de lava de $60 \mathrm{~m}$ de diâmetro

\begin{tabular}{c|c|c|c}
\hline $\begin{array}{c}\text { Profundi- } \\
\text { dade } \\
(\mathrm{m})\end{array}$ & $\begin{array}{c}\text { Volume de } \\
\text { rocha } \\
\left(\mathrm{m}^{3}\right)\end{array}$ & $\begin{array}{c}\mathrm{H}_{2} \mathrm{O} \\
(\%)\end{array}$ & $\begin{array}{c}\text { Volume } \\
\text { d'água } \\
(\ell)\end{array}$ \\
\hline $\begin{array}{c}\text { Superficie-150 } \\
150-375\end{array}$ & 110445,0 & 9,5 & 10193798,0 \\
$375-500$ & 3328051,2 & 8,2 & 36248198,0 \\
$500-750$ & 858162,5 & 7,3 & 24294400,0 \\
$750-1000$ & 1088237,5 & 5,0 & 54922400,0 \\
$1000-1500$ & 2760825,0 & 3,0 & 82824650,0 \\
\hline Total 1 500* & $5592521,0 * *$ & - & $262.995321,0$ \\
\hline
\end{tabular}

* Velocidade de lançamento da lava $=40 \mathrm{~m} / \mathrm{s}$

** Coluna de lava de $60 \mathrm{~m}$ de diâmetro

CONCLUSÃO O modelo de implosão-fluidização concebe a origem dos pipes a partir de uma explosão interna (implosão) em conseqüência da acumulação de energia devida ao aquecimento da água dos poros de sedimentos que são atravessados por uma coluna de lava. A energia liberada no momento em que há uma descompressão súbita do sistema, é calculada e provada ser mais que suficiente para proporcionar o surgimento de um pipe de comprimento comparável àqueles de pipes conhecidos. A fluidização, admitida por diversos autores, porém nunca analisada em detalhe, pode se fazer unicamente a partir do vapor d'água originado dos sedimentos aquecidos, sem que seja considerada a contribuição dos gases vulcanomagmáticos. Cálculos feitos a partir da observação da geologia dos pipes e do estudo granulométrico de suas brechas permitiram não somente o dimensionamento físico de todo o fenômeno, mas também uma explicação para a característica interna das formações 
tais como a zonalidade das brechas, o arredondamento e a mistura de elementos de brecha de profundidades diversas, as "gotas" etc.

Com o modelo, são solucionados os problemas propostos por Fisher (1955) sobre a fraca velocidade de percolação dos gases, por McBirney (1963) sobre a impossibilidade da origem profunda de grandes volumes de gás, e por Shimazu (1961) sobre a difusividade dos gases nas rochas, impedindo sua acumulação em profundidade. Explica-se ainda a origem dos pipes "cegos" (que não atingem a superficie), a posição estrutural dos pipes, sempre ao lado de falhas mas raramente nos seus eixos de fraturamento, e o tipo de enraizamento laminar dos pipes sul-africanos observados por Nixon (1973) e Bardet (19.73). O modelo de implosão-fluidização deve ser julgado pela sua propensão a explicar todos os problemas acima propostos.

Agradecimentos Ao Professor R. Brousse por suas críticas e por ter posto à minha disposição os meios analíticos de seu laboratório na Fac. de Orsay, França.

Agradeço também à direção da METAMIG Metais de Minas Gerais S/A - que me deu a pos sibilidade em tempo e recursos para a elaboração do artigo.

\section{BIBLIOGRAFIA}

BARDET, M. - 1973 - Géologie du diamant. Mémoires du BRGM, n. ${ }^{\circ} 83$ - Éditions du BRGM, $235 \mathrm{pp}$.

BIONDI, J.C. - 1974 - Contribution à la connaissance des cheminées bréchiques d'origine volcanique. Tese de doutorado, Universidade de Paris - Sud., Orsay.

BOWES, D.R. e WRIGHT, A.E. - 1967 - The explosion - breccia pipes near Kentalen, Scotland, and their geological setting. Trans. Roy. Soc. Edin., 68 (5): 109-143.

CARMAN, P.C. - 1937 - Fluid flow through granular beds. Trans. Inst. Chem. Eng. 15: 150-166.

DAWSON, J.B. - 1962 - Basutoland Kimberlites. Bull. Geolo. Soc. Amer. (73): 545-560.

FISHER, W.M. - 1955 - The production of steam from drill holes at Wairakei. N. Zealand Dept. Sci. and Industr. Res. Bull. (117): 75-102.

FOLK, R.L. e WARD, W.C. - 1957 - Brazos River bar: a study in the significance of grain size parameters. Journ. Sed. Petr. 27 (1): 3-26.

GOGUEL J. - 1953 - Le régime thérmique de l'eau souterraine. Ann, des Mines. 142(10): 3-31.

KENNEDY, G.C. e NORDLIE, B.E. - 1968 - The genesis of diamond deposits. Econ. Geol. 63: $498-499$.

LEVA, M. - 1947 - Pressure drop through packed tubes. Chem. Eng. Progress. 43(11): 633-650.

LEVA, M., GRUMNER, M., WEINTRAUB, M. e POLLCHICK, M. - 1948 - Principles of fluidization. Chem. Eng. Progress. 44(7): 511-520.

LORENZ, V., MCBIRNEY, A.R. e WILLIANS, H. - 1970 - An investigation of volcanic depressions: maars, tuffrings, tuffcones and diatremes. NASA Research Grant report, NGR 38-003-012, $198 \mathrm{pp.}$

MCBIRNEY, A.R. - 1959 - Factors governing emplacement of volcanic necks. Amer Journ. Sci. (257): 431-448.

MCBIRNEY, A.R. - 1963 - Breccia pipe near Cameron, Arizona - A discussion. Geol, Soc. Amer. Bull. (74): 227-232.

MCBIRNEY, A.R. $-1970-$ Factors governing the formation of pyroclastic rocks. Bull Volc. 34(2): 372-384.

MCGETCHIN, T.R. - 1972 - A crustal upper-mantle model for the Colorado Plateau based on observations of crystalline rock fragments in the Moses rock dykes. Journ. Geoph. Res. 77 (35): 7022-7032.

MCGETCHIN, T.R. e WAYNE, U.G. - 1973 - Xenoliths in maars and diatremes with inference for the Moon, Mars and Venus. Journ. Geol. Res. 78(11): 1833-1853.

MIKHEYENKO, V.I. e NENASHEV, N.I. - 1961 -- Absolute age of formation and relative age of intrusion of the Kimberlite of Yakutie. Int. Geol. Rev. 4(8): 916-924.

NIXON, P.H. - 1973 - Lesotho Kimberlites. Lesotho Nat. Dev. Corp.-Maseru, Cape and Transvaal Printers Ltd., Cape Town, $350 \mathrm{pp}$.

POLDEVAART, A. e HESS, H.H. - 1968 - Basalts. John Wiley \& Sons, New York, 2 volumes, 862 pp.

REYNOLDS, D.L. - 1954 - Fluidization as a geological process and its bearing on the problem of intrusive granites. Amer. Journ. Sci. (252): 577-614.

RITTMANN, A. - 1963 - Les volcans et leur activìté. Masson \& Cie, Paris, 461 pp.

WILLSHIRE, H.G. - 1961 - Layered diatremes near Sydney, New South Wales. Journ. Geol. 69 (4): 473-484 